INRA Prod. Anim.,

2011, 24 (3), 245-258

\title{
Origines alimentaires et digestion des nutriments chez le veau préruminant
}

\author{
F. GAUTIER ${ }^{1}$, E. LABUSSIÈRE 2,3 \\ ${ }^{1}$ Institut de l'Elevage, Monvoisin, BP 85225, F-35652 Le Rheu, France \\ 2 INRA, UMR1079 Systèmes d'Elevage, Nutrition Animale et Humaine, F-35390 Saint-Gilles, France \\ 3 Agrocampus Ouest, Systèmes d'Elevage, Nutrition Animale et Humaine, F-35000 Rennes, France \\ Courriel : etienne.labussiere@rennes.inra.fr
}

\begin{abstract}
Depuis le début de l'utilisation des aliments d'allaitement pour les veaux de boucherie, les sources de nutriments se sont diversifiées par l'emploi de divers produits d'origines animale et végétale. Malgré les traitements visant à améliorer leur digestion, ces produits sont en général moins bien valorisés par le veau que le lait entier. La connaissance de leur digestibilité est primordiale pour rationnaliser leur emploi dans les aliments d'allaitement.
\end{abstract}

\begin{abstract}
La production du veau de boucherie a connu beaucoup d'évolutions concernant la race des animaux (généralisation de la race Prim'Hosltein) et leur durée d'élevage (allongement des durées d'élevage entraînant un accroissement du poids vif des animaux en fin d'engraissement). Ces évolutions ont eu des conséquences en termes nutritionnels nécessitant de réactualiser les besoins en protéines et en énergie des veaux (diminution de l'apport en protéines à la fin de l'engraissement, nouvelles équations de calcul des besoins en énergie) (Labussière 2008). De plus, les sources de nutriments utilisées dans les aliments d'allaitement se sont diversifiées sous l'influence des fluctuations du prix des matières premières laitières (forte hausse en 2007) et de l'évolution de la réglementation européenne (annulation de la prime d'incorporation de la poudre de lait écrémé dans les aliments d'allaitement en 2006). Dans le but d'équilibrer les apports face aux besoins nutritionnels en utilisant ces nouvelles sources de nutriments, l'objet de ce texte est de réaliser une synthèse des résultats et travaux disponibles sur les caractéristiques des protéines, lipides et glucides de l'aliment d'allaitement et sur leur digestion chez le veau de boucherie.
\end{abstract}

\section{1 / Apports et digestion des protéines}

\section{1 / Les sources protéiques des aliments d'allaitement}

\section{a) Les protéines laitières}

L'exploitation industrielle et commerciale des protéines laitières est née de la volonté de valoriser les excédents laitiers et les coproduits, issus notamment de la fromagerie. Les fluides laitiers desquels sont extraites ou concentrées les protéines sont principalement le lait écrémé, les lactosérums et les babeurres (respectivement coproduits de la fromagerie et de la beurrerie). Ces produits sont systématiquement séchés avant leur introduction dans les formules d'aliment d'allaitement.

La poudre de lait écrémé, obtenue après élimination des Matières Grasses (MG) par centrifugation du lait entier, présente une teneur élevée en Matières Azotées Totales (MAT), $36 \%$ de la Matière Sèche, (MS) (tableau 1), constituées majoritairement de caséines. En revanche, la poudre de lactosérum contient toutes les protéines solubles du lait qui ne participent pas à la coagulation, soit une quantité importante de lactoglobuline $(45 \%$ des protéines du lactosérum), de lactalbumine (25\%) et de globulines $(11,5 \%)$ (Jeantet et al 2008). Il existe deux classes de poudre de lactosérum différant dans leur composition chimique selon le procédé industriel appliqué :

- La poudre de lactosérum doux, issue des fabrications de fromages à pâte pressée cuite et non cuite et des fromages à pâte molle.

- La poudre de lactosérum acide, issue des fabrications des fromages à pâte fraîche et des caséinates.

Les poudres de lactosérum acide sont plus riches en minéraux ( $12 \%$ de la MS) que celles de lactosérum doux (9\% de la MS) mais ont une teneur plus faible en MAT (10\% vs 13\%). Les concentrés de protéines sériques sont des ingrédients dérivés du lactosérum auxquels on a soustrait l'eau, les minéraux et le lactose. On les obtient en enlevant assez de constituants non-protéiques du lactosérum pour que le produit fini sec contienne la proportion de protéines souhaitée (environ 35\%). Le babeurre est issu de la matière aqueuse libérée par le barattage lors de la fabrication du beurre. Après séchage, la poudre de babeurre est composée principalement de lactose $(43 \%)$, de protéines laitières $(33 \%)$ et de minéraux (10\%) (tableau 1).

Du fait de la ségrégation de certaines protéines (essentiellement des caséines) lors des processus de l'industrie laitière, les profils en Acides Aminés (AA) de la poudre de babeurre, de la poudre de lactosérum et du concentré de protéines sériques diffèrent de celui de la poudre de lait écrémé. Ainsi, la poudre de lactosérum et le concentré de protéines sériques présentent notamment des teneurs plus faibles en AA aliphatiques (valine et leucine) et en histidine mais des teneurs plus importantes en thréonine. Le concentré de protéines sériques est également plus concentré en AA soufrés (méthionine et cystéine) et en lysine que les autres matières premières laitières, avec une teneur en lysine égale à $9,1 \%$ de la MAT. La poudre de babeurre a un profil en AA très proche de celui de la poudre de lait écrémé ; elle présente cependant une teneur légèrement plus faible en AA soufrés. Mise à part de légères carences par rapport aux recommandations, le profil en AA des matières premières issues de l'industrie laitière est assez équilibré par rapport aux recommandations nutritionnelles (tableau 1). 
Tableau 1. Composition chimique et valeur nutritionnelle des principales matières premières protéiques utilisées dans la formulation des aliments d'allaitement pour veaux de boucherie.

\begin{tabular}{|c|c|c|c|c|c|c|c|c|c|}
\hline & $\begin{array}{l}P .^{(1)} \text { lait } \\
\text { écrémé }\end{array}$ & $\begin{array}{c}P .^{(1)} \\
\text { babeurre }\end{array}$ & $\begin{array}{l}\mathbf{P}^{(1)} \\
\text { lactosé- } \\
\text { rum } \\
\text { doux }\end{array}$ & $\begin{array}{l}P^{(1)} \\
\text { lactosé- } \\
\text { rum } \\
\text { acide }\end{array}$ & $\begin{array}{c}\text { Concentré } \\
\text { de } \\
\text { protéines } \\
\text { sériques à } \\
35 \%\end{array}$ & $\begin{array}{c}\text { Concentrat } \\
\text { de soja }\end{array}$ & $\begin{array}{l}\text { Gluten de } \\
\text { blé } \\
\text { hydrolysé }\end{array}$ & $\begin{array}{c}\text { Concentré } \\
\text { protéique } \\
\text { de pomme } \\
\text { de terre }\end{array}$ & $\begin{array}{l}\text { Recomman- } \\
\text { dations }^{(2)}\end{array}$ \\
\hline Teneur en $\mathrm{MS}^{(1)}(\%)$ & 94,7 & 95,8 & 96,4 & 98,0 & 96,0 & 94,4 & - & 92,3 & \\
\hline \multicolumn{10}{|l|}{ Composition $^{(3)}$ (\% MS) } \\
\hline $\mathrm{MAT}^{(1)}(\mathrm{N} \times 6,25)$ & 36,0 & 32,5 & 13,1 & 9,9 & 37,1 & 66,9 & 85,7 & 84,1 & \\
\hline $\mathrm{MG}^{(1)}$ & 1,7 & 6,3 & 2,2 & 2,2 & 2,2 & - & 8,2 & 1,0 & \\
\hline Lactose & 50,5 & 43,4 & 75,6 & 64,3 & 50,5 & - & - & - & \\
\hline Amidon & - & - & - & - & - & - & - & 0,7 & \\
\hline $\mathrm{MM}^{(1)}$ & 8,6 & 9,9 & 9,0 & 12,0 & 5,9 & 6,5 & 3,1 & 2,8 & \\
\hline $\begin{array}{l}\text { Energie brute } \\
\text { (MJ/kg de MS) }\end{array}$ & 18,3 & 18,1 & 16,2 & 15,4 & 18,2 & 20,1 & - & 22,2 & \\
\hline Lysine (\% MAT) & 7,9 & 7,8 & 7,4 & 7,4 & 9,1 & 6,2 & 1,5 & 7,6 & $8,5^{(4)}$ \\
\hline \multicolumn{10}{|l|}{$\begin{array}{l}\text { Profil en acides } \\
\text { aminés (\% lysine) }\end{array}$} \\
\hline Thréonine & 56 & 60 & 76 & 74 & 77 & 65 & 170 & 73 & 58 \\
\hline Tryptophane & 17 & 16 & 17 & 17 & 18 & 20 & 59 & 16 & 11 \\
\hline $\begin{array}{l}\text { Méthionine+ } \\
\text { Cystéine }\end{array}$ & 46 & 44 & 45 & 44 & 54 & 48 & 281 & 47 & 51 \\
\hline Valine & 78 & 73 & 69 & 67 & 65 & 82 & 278 & 87 & 72 \\
\hline Isoleucine & 69 & 60 & 73 & 72 & 68 & 77 & 286 & 75 & 67 \\
\hline Leucine & 119 & 123 & 112 & 107 & 111 & 120 & 503 & 129 & 103 \\
\hline Histidine & 35 & 33 & 26 & 26 & 22 & 44 & 148 & 29 & 31 \\
\hline
\end{tabular}

(1) MS : Matière Sèche, MAT : Matières Azotées Totales, MG : Matières Grasses, MM : Matières Minérales, P. : Poudre.

(2) Moyennes des valeurs de recommandations pour les stades croissance et finition (d'après Toullec 1988).

(3) Composition chimique : poudre de babeurre (sauf acides aminés), concentré de protéines sériques, concentrat de soja (d'après Toullec 1988) ; gluten de blé hydrolysé (d'après Toullec et Formal 1998) ; poudre de lait écrémé, poudre de lactosérum doux et acide, concentré protéique de pomme de terre (d'après Sauvant et al 2004) ; acides aminés de la poudre de babeurre (d'après C. Roger, communication personnelle).

(4) Valeur correspondant à la pratique (besoin non estimé).

\section{b) Les protéines végétales}

Les sources de protéines végétales sont diverses (concentrat de soja, gluten de blé hydrolysé, concentré protéique de pomme de terre) (tableau 1). Le soja est actuellement très employé dans les aliments d'allaitement mais les dérivés du soja peuvent générer des réactions d'hypersensibilité digestive, nécessitant une dénaturation poussée des protéines du soja par voie physico-chimique ou enzymatique. Les concentrats, dépourvus d'oligosides, et surtout les isolats, pratiquement dépourvus de glucides sources d'inconfort digestif (Kandra et Gyemant 2000) sont donc plus utilisés que les farines. Le gluten de blé hydrolysé est un coproduit de la production d'amidon. Il subit une hydrolyse enzymatique le rendant soluble. Il présente une forte teneur en MAT $(86 \%$ de la MS). Le concentré protéique de pomme de terre (teneur en MAT : 84\% de la MS) possède des facteurs antinutritionnels (solanine) qui peuvent entraîner des troubles importants (diarrhée, refus, perte de poids, chute de poils) s'amplifiant avec le taux d'incorporation et l'âge des veaux (Troccon et Toullec 1989). Aucune étude n'a montré que les traitements technologiques pouvaient être suffisants pour éliminer tous les facteurs antinutritionnels du concentrat de pomme de terre qui n'est utilisé qu'à un faible taux d'incorporation (2 à 5\%).
Le concentrat de soja et le concentré protéique de pomme de terre ont une teneur en lysine $(6,2$ et $7,6 \%$ de la MAT, respectivement) plus élevée que celle du gluten de blé hydrolysé $(1,5 \%$ de la MAT). Les protéines végétales présentent également des profils en AA plus déséquilibrés par rapport aux recommandations nutritionnelles que les produits laitiers. Elles doivent donc être rééquilibrées au moment de la formulation.

\section{2 / La digestion dans la cail- lette}

Chez le veau préruminant nourri avec un aliment d'allaitement, la prise alimentaire est souvent rapide (cinq à dix minutes environ). Grâce au phénomène de contraction des deux lèvres de la gouttière œsophagienne stimulé par l'ingestion d'un liquide, l'aliment liquide ingéré par le veau passe directement de l'œsophage à la caillette sans transiter par le rumen (Guilhermet et al 1975). De plus, les glandes salivaires du veau préruminant, sont immatures et sécrètent peu de salive (Guilloteau et al 1995). Celle-ci est dépourvue d'enzymes protéolytiques (Sissons 1981). La digestion des protéines ne commence donc que dans la caillette sous l'action des protéases gastriques.

La muqueuse glandulaire de la caillette sécrète trois endopeptidases (sous forme de zymogènes) : la chymosine, la pepsine A et la pepsine B. Ces enzymes sont activées par hydrolyse sous l'action de l'acide chlorhydrique en milieu acide ( $\mathrm{pH} \leq 5$; Caugant 1993) puis vont précipiter spécifiquement les caséines-Kappa du lait générant un coagulum constitué des protéines et des MG. Contrairement aux caséines, les protéines sériques (protéines solubles du lait) et les protéines végétales utilisées dans les aliments d'allaitement ne sont pas soumises au phénomène de coagulation. Par la suite, nous ferons donc la distinction entre les protéines coagulantes et les protéines non coagulantes puisque ce facteur conditionne des cinétiques digestives très différentes.

a) La digestion des protéines coagulant dans la caillette

Le lait entier et les aliments d'allaitement à base de poudre de lait écrémé contiennent suffisamment de caséines (de type Kappa) pour coaguler dans la caillette. La coagulation résulte de la déstabilisation de l'édifice micellaire des caséines par acidification du milieu et hydrolyse de la liaison Phénylalanine 105 - Méthionine 106 de la caséine Kappa (Ribadeau-Dumas 1979). Cette hydrolyse aboutit à la formation de deux composés, la para-caséine-Kappa et le caséinomacropeptide et provoque 
l'agrégation des micelles de caséines pour former le coagulum. Cependant, la formation du coagulum peut être altérée en cas d'un traitement thermique excessif du lait (Toullec et Lallès 1995).

La cinétique de la réaction de coagulation est de type michaelienne et sa vitesse est directement proportionnelle à la quantité de pepsines et de chymosine sécrétées dans le contenu de la caillette. La chymosine possède une activité coagulante qui est deux à trois fois plus élevée que celle de la pepsine A (Martin et al 1981) et quatre à six fois plus élevée que celle de la pepsine $\mathrm{B}$ (Martin et al 1982). Quantitativement, elle ne représente qu'environ 5\% des pepsines totales (Valles 1980). Néanmoins, la muqueuse de la caillette d'un veau de boucherie âgé de cinq mois contient encore 60 fois plus d'activité que nécessaire pour coaguler rapidement la totalité de l'aliment lacté ingéré quotidiennement (Toullec et Lallès 1995). La vitesse de coagulation dépend également de la valeur du $\mathrm{pH}$, et elle est maximale pour un $\mathrm{pH}$ égal à 5,6 (Carlson et al 1987). Chez le veau préruminant, le $\mathrm{pH}$ dans la caillette étant compris entre 4,5 et 6,2 immédiatement après le repas, le coagulum se forme rapidement (d'une à dix minutes) après l'ingestion de l'aliment (Toullec et Lallès 1995) et persiste dans la caillette pendant au moins quatre heures (Miyazaki et al 2009). Ceci entraîne alors une rétention prolongée des protéines qui subissent un début d'hydrolyse enzymatique sous l'action des pepsines et de la chymosine. L'hydrolyse s'intensifie avec la chute de $\mathrm{pH}$ consécutive au repas et est maximale lorsque le $\mathrm{pH}$ gastrique est compris entre 2,1 et 3,5 (valeurs optimales du $\mathrm{pH}$ pour la protéolyse par la pepsine et la chymosine; Henschel 1973). Ces conditions se maintiennent au cours des trois à quatre heures après le repas chez le veau préruminant (Toullec et Lallès 1995).

Ainsi, les digesta duodénaux du veau contiennent peu de caséines intactes audelà des dix premières minutes postprandiales (Scanff et al 1990) et après six heures de digestion, les peptides évacués sont presque exclusivement d'origine caséique (Yvon et al 1986). Seule une petite fraction (environ 15\%) des caséines atteint le duodénum sous forme faiblement ou non protéolysée (Yvon et al 1986), pouvant correspondre à la caséine $\alpha$ s2, plus hydrophile que la caséine $\alpha s 1$ et relativement résistante à l'hydrolyse des enzymes gastriques (Guilloteau 1986). Le caséinomacropeptide atteint également le duodenum du veau sous la forme non protéolysée (Scanff et al 1992a). b) La digestion des protéines ne coagulant pas dans la caillette

Les autres protéines ne coagulent pas dans la caillette, ce qui entraîne une accélération de l'évacuation gastrique des matières azotées dont la cinétique dépend du taux de substitution des caséines, de la source de protéines et du traitement technologique qui leur est appliqué (Toullec et al 1971). Leur temps de séjour dans la caillette très court (10 à 30 minutes, Scanff et al 1990) diminue leur degré d'hydrolyse par les protéases gastriques (Toullec et al 1975, Caugant et al 1993). Ainsi, quand les protéines de lactosérum sont utilisées en substitution aux caséines de la poudre de lait écrémé, la quantité totale de matières azotées évacuée de la caillette au cours de la première heure post-prandiale est plus importante $(36 \%$ et $23 \%$ de la quantité ingérée pour les protéines de lactosérum et la poudre de lait écrémé, respectivement ; Toullec et al 1971). De plus, les protéines du lactosérum (lactoferrine, $\alpha$-lactalbumine et $\beta$-lactoglobuline) sont peu dégradées dans la caillette et parviennent sous forme quasi-native dans le contenu du duodénum proximal (Scanff et al 1992b). Toutefois, l'acidification de la poche gastrique, entraîne environ trois heures après le repas la protéolyse de l' $\alpha$-lactalbumine restante, mais qui ne représente plus que $50 \%$ de la quantité ingérée (Yvon et al 1984). Les protéines végétales, ne formant pas de coagulum dans la caillette, y sont également peu retenues et dégradées. Ainsi, trois heures après le repas, la quantité d'azote protéique parvenant au duodénum est plus importante avec des aliments à base de soja et de féverole qu'avec un aliment à base de poudre de lait écrémé (1,7 et 2,3 fois plus élevées respectivement ; Guilloteau et al 1979). De même, six heures après le repas, les protéines de réserve du soja (glycinine et $\beta$-conglycinine) sont encore présentes sous forme native dans le contenu duodénal (Toullec et Lallès 1995). En l'absence de phénomène de coagulation, l'hydrolyse des protéines dans la caillette est restreinte et la digestion des protéines de substitution se situe principalement dans l'intestin grêle.

\section{3 / La digestion dans l'intestin grêle}

La sécrétion de bile dans le contenu duodénal élève la valeur du $\mathrm{pH}$ intestinal à un niveau proche du $\mathrm{pH}$ optimal d'activité des enzymes pancréatiques (entre 7,5 et 8,5) tout en inhibant l'activité des enzymes gastriques. Ainsi, à leur arrivée dans l'intestin grêle, les peptides sont soumis à l'action des endopeptidases pancréatiques (trypsine, chymotrypsine et élastases) qui hydro- lysent les liaisons peptidiques à l'intérieur des molécules au niveau des fonctions acides des AA basiques, aromatiques et aliphatiques (Guilloteau et al 1995). Les carboxypeptidases du suc pancréatique libèrent ensuite les $\mathrm{AA}$, à partir de l'extrémité $\mathrm{C}$ terminale des peptides formés. L'action des enzymes intestinales sur les protéines sortant de la caillette aboutit à la formation d'un mélange contenant $70 \%$ de petits peptides (composés de deux à six AA) et $30 \%$ d'AA libres dans le contenu intestinal (Toullec et Lallès 1995).

L'hydrolyse des di-, tri- et oligopeptides restants se poursuit ensuite au niveau de la bordure en brosse des entérocytes où ils sont dégradés par l'action des carboxypeptidases et de la trypsine du suc pancréatique et par les aminopeptidases, ainsi que les peptidases contenues dans la membrane des entérocytes (Montagne 2000). Ainsi, les oligopeptides y sont convertis par la protéolyse en tri et dipeptides et environ $60 \%$ des tripeptides et $10 \%$ des dipeptides y sont également hydrolysés. Les peptides restants pénètrent dans le cytoplasme des entérocytes où ils finissent d'être hydrolysés en AA libres sous l'action d'aminotripeptidases et d'aminodipeptidases et sont ensuite absorbés par l'intestin grêle (Toullec et Lallès 1995).

\section{4 / Les principaux facteurs de variation}

\section{a) Le temps de séjour moyen}

L'intensité de digestion et le Temps de Séjour Moyen (TSM) des protéines des digesta dans le tube digestif sont corrélés positivement (Lallès 1988), le TSM déterminant la durée d'action des enzymes. Chez le veau préruminant, l'origine des sources protéiques et le phénomène de coagulation dans la caillette peuvent influencer le TSM des protéines. Chez le veau nourri au lait, le TSM des digesta dans l'ensemble du tube digestif est de 20 à 27 heures (Miller et al 1967, Lallès 1988). Dans le cas de protéines coagulant dans la caillette, la phase liquide, contenant le lactose et les matières minérales, est évacuée plus rapidement de la caillette que les caséines et les lipides formant le coagulum (Miller et al 1967, Faichney 1983). Ainsi au cours des six premières heures postprandiales, les quantités parvenant dans le duodénum représentent $80 \%$ des quantités ingérées dans le cas du lactose et des matières minérales, et seulement 55 et $47 \%$ des quantités ingérées dans le cas des caséines et des lipides respectivement (Toullec et al 1971). En absence de coagulation des protéines, les digesta sont évacués plus rapidement de la caillette (Toullec et al 1971, Caugant 1993). Ainsi, lorsque les 
Tableau 2. Facteurs de variation de l'utilisation digestive apparente fécale de l'azote des principales matières premières protéiques utilisées dans la formulation d'aliments d'allaitement pour veaux de boucherie.

\begin{tabular}{|c|c|c|c|c|c|}
\hline $\begin{array}{l}\text { Facteurs de } \\
\text { variation }\end{array}$ & Sources protéiques & Coagulation & $\begin{array}{l}\text { Age des } \\
\text { veaux (j) }\end{array}$ & $\begin{array}{l}\text { Digestibilité } \\
\text { apparente fécale de } \\
\text { l'azote (\%) }\end{array}$ & Références \\
\hline \multirow[t]{2}{*}{$\begin{array}{l}\text { Coagulation } \\
\text { dans la caillette }\end{array}$} & $\begin{array}{l}\text { Poudre de lait écrémé } \\
\text { avec addition d'HCl } \\
\text { avec addition de citrate de sodium }\end{array}$ & $\begin{array}{l}\text { oui } \\
\text { non } \\
\text { non }\end{array}$ & $\begin{array}{l}51-101 \\
51-101 \\
51-101\end{array}$ & $\begin{array}{l}96,2 \\
95,6 \\
95,3\end{array}$ & $\begin{array}{l}\text { Toullec et al } \\
\quad(1974)\end{array}$ \\
\hline & $\begin{array}{l}\text { Poudre de lait écrémé }(65 \%) \text { et poudre } \\
\text { de lactosérum }(10 \%)\end{array}$ & $\begin{array}{l}\text { oui } \\
\text { non }\end{array}$ & $\begin{array}{l}25 \\
25\end{array}$ & $\begin{array}{l}92,3 \\
90,9\end{array}$ & $\begin{array}{l}\text { Petit et al } \\
(1989)\end{array}$ \\
\hline \multirow{4}{*}{$\begin{array}{l}\text { Traitement } \\
\text { technologique }\end{array}$} & $\begin{array}{l}\text { Concentré de protéines sériques } \\
\text { séché à } 72^{\circ} \mathrm{C} \text { pendant } 15 \mathrm{~s} \text {. } \\
\text { séché à } 75^{\circ} \mathrm{C} \text { pendant } 30 \mathrm{~min} .\end{array}$ & $\begin{array}{l}\text { oui } \\
\text { oui }\end{array}$ & $\begin{array}{l}31 \\
31\end{array}$ & $\begin{array}{l}89,0 \\
94,0\end{array}$ & $\begin{array}{c}\text { Grongnet et } \\
\text { al (1981) }\end{array}$ \\
\hline & $\begin{array}{l}\text { Concentrat de soja } \\
\text { extrait à l'alcool } \\
\text { traité à l'acide }\end{array}$ & $\begin{array}{l}\text { oui } \\
\text { oui }\end{array}$ & $\begin{array}{l}35-42 \\
35-77\end{array}$ & $\begin{array}{l}88,0 \\
70,0\end{array}$ & $\begin{array}{l}\text { Troccon et } \\
\text { Toullec } \\
(1989)\end{array}$ \\
\hline & $\begin{array}{l}\text { Gluten de blé } \\
\text { vital } \\
\text { dévitalisé }\end{array}$ & $\begin{array}{l}\text { oui } \\
\text { oui }\end{array}$ & $\begin{array}{l}49-91 \\
49-91\end{array}$ & $\begin{array}{l}94,0 \\
93,0\end{array}$ & $\begin{array}{l}\text { Toullec et } \\
\text { Grongnet } \\
(1990)\end{array}$ \\
\hline & $\begin{array}{l}\text { Protéines de soja } \\
\text { Farine de soja chauffée } \\
\text { Isolat de protéines de soja hydrolysées }\end{array}$ & $\begin{array}{l}\text { non } \\
\text { non }\end{array}$ & $\begin{array}{l}12-68 \\
12-68\end{array}$ & $\begin{array}{l}59,0 \\
90,0\end{array}$ & $\begin{array}{l}\text { Lallès et al } \\
\qquad(1995)\end{array}$ \\
\hline
\end{tabular}

protéines de lait sont remplacées par des protéines de soja ou de lactosérum, la fraction protéique ingérée quitte la caillette respectivement trois et six heures après ingestion pour les protéines de soja (plus solubles) et de lactosérum (Caugant 1993). La durée de transit des digesta dans l'intestin grêle est rapide, de l'ordre de 2,5 heures (Miller et al 1967, Dardillat et Marrero 1977), le contenu digestif étant surtout retenu dans le gros intestin (12 à 18 heures).

L'addition d'acide chlorhydrique ou de citrate de sodium pour supprimer la coagulation de la poudre de lait écrémé n'affecte pas l'utilisation digestive des protéines (en moyenne 95,5 vs 96,2\% ; Toullec et al 1974) (tableau 2). De même, la suppression de la coagulation des protéines par addition d'oxalate de sodium ne modifie pas notablement l'utilisation digestive des protéines d'un aliment d'allaitement constitué de $65 \%$ de poudre de lait écrémé et de $10 \%$ de poudre de lactosérum (en moyenne 91,6\%; Petit et al 1989) (tableau 2).

\section{b) L'âge}

La quantité de certaines sécrétions digestives libérées dans l'organisme évolue avec l'âge de l'animal (Ternouth et al 1976, Guilloteau 1986). Ainsi, les quantités journalières de suc gastrique sécrétées augmentent de 8 à $13 \mathrm{~g} / \mathrm{kg}$ de Poids Vif (PV) jusqu'à 9 semaines puis diminuent jusqu'à $7 \mathrm{~g} / \mathrm{kg} \quad \mathrm{PV}$ à 30 semaines (Guilloteau et al 1980). La quantité d'acide chlorhydrique sécrétée par la caillette, élevée à la naissance $(1,5 \mathrm{mEq} / \mathrm{kg} \mathrm{PV} / \mathrm{j})$, diminue au cours de la période d'élevage $(1,25 \mathrm{mEq} / \mathrm{kg} \mathrm{PV} / \mathrm{j}$ à sept semaines et $0,5 \mathrm{mEq} / \mathrm{kg} \mathrm{PV} / \mathrm{j}$ à quatre mois, Guilloteau 1986). En revanche, la quantité de pepsine présente dans la muqueuse gastrique ne change pas avec l'âge, tandis que celle de chymosine est maximale à deux jours puis diminue. Elle reste cependant suffisante pour coaguler rapidement la totalité du lait ingéré (Le Hüerou et al 1990). Dans le pancréas, les activités et les quantités de la plupart des enzymes protéolytiques sont minimales à deux jours et augmentent ensuite jusqu'à deux mois (Le Hüerou et al 1990). Ainsi, 12 heures après l'ingestion du repas, la quantité de protéases sécrétées dans la lumière de l'intestin grêle augmente de $8,2 \mathrm{mg} / \mathrm{kg}$ de PV à $84,9 \mathrm{mg} / \mathrm{kg}$ de PV pour des âges respectifs de 7 et 63 jours (Ternouth et al 1976). Cependant, les sécrétions pancréatiques peuvent être sub-limitantes chez le veau âgé de plus de deux mois lors du remplacement des protéines du lait par d'autres sources protéiques (Guilloteau et al 2011).

La quantité d'aliment d'allaitement ingérée par le veau évolue également avec l'âge. Elle augmente de 4 à $10 \mathrm{~g}$ $\mathrm{MS} / \mathrm{kg}$ de PV au cours du premier mois de vie puis diminue jusqu'à $7 \mathrm{~g} \mathrm{MS} / \mathrm{kg}$ $\mathrm{PV}$ environ à l'âge de 5 mois. L'effet de l'âge sur la digestibilité des protéines des aliments d'allaitement a été largement étudié, notamment pour les protéines apportées par le lait écrémé ou la poudre de lait écrémé. Les principaux résultats regroupés sur la figure 1, indiquent que la digestibilité apparente fécale des protéines du lait augmente de $84 \%$ à $93 \%$ jusqu'au 37 ème jour de vie, mais n'évolue plus au-delà de cet âge (Toullec 1988) (figure 1). On observe une évolution similaire pour la digestibilité des sources végétales de protéines au cours du premier mois d'âge (figure 1). Les valeurs rapportées par Huber (1975) pour le concentré protéique de poisson, indiquent cependant un accroissement de l'utilisation digestive des protéines jusqu'à environ 100 jours (Huber 1975) (figure 1).

\section{c) Le traitement technologique}

Les protéines de la poudre de lait écrémé sont digérées avec une grande efficacité (96\%, Toullec et al 1974) (tableau 2). Les protéines de la poudre de lactosérum doux ont une digestibilité légèrement plus faible mais qui peut être augmentée par un accroissement de la durée de séchage de la poudre (de 89 à 94\%, Grongnet et al 1981) (tableau 2). En revanche, la digestibilité apparente fécale des protéines végétales est généralement inférieure et dépend beaucoup des traitements technologiques qui leur sont appliqués. En effet, les sources de protéines végétales contiennent souvent 
Figure 1. Effet de l'âge du veau préruminant sur l'utilisation digestive des protéines de l'aliment d'allaitement.

Source de protéines :

x : lait entier ou poudre de lait entier (Raven et Robinson 1958, Neergaard 1979)

+ : lait écrémé ou poudre de lait écrémé (Raven et Robinson 1958, Roy et al 1970, Toullec et al 1974, Huber 1975, Grongnet et al 1981, Akinyele et Harshbarger 1983, Ternouth et al 1985, Toullec 1988, Toullec et al 1994, Lallès et al 1995, Diaz et al 2001, Labussière et al 2009)

+ : poudre de lait écrémé, sans coagulation (Toullec et al 1974)

- : concentrat de soja (Nitsan et al 1972, Akinyele et Harshbarger 1983)

^ : concentré de protéines de pomme de terre (Troccon et Toullec 1989)

$\checkmark$ : concentré de protéines de poisson (Huber 1975)

o : composition mixte, sans protéines végétales (Roy et al 1970, Grongnet et al 1981, Dawson et al 1988, Toullec et al 1994, Terosky et al 1997)

• : composition mixte, avec des protéines végétales (Neergaard 1979, Lallès et al 1995)
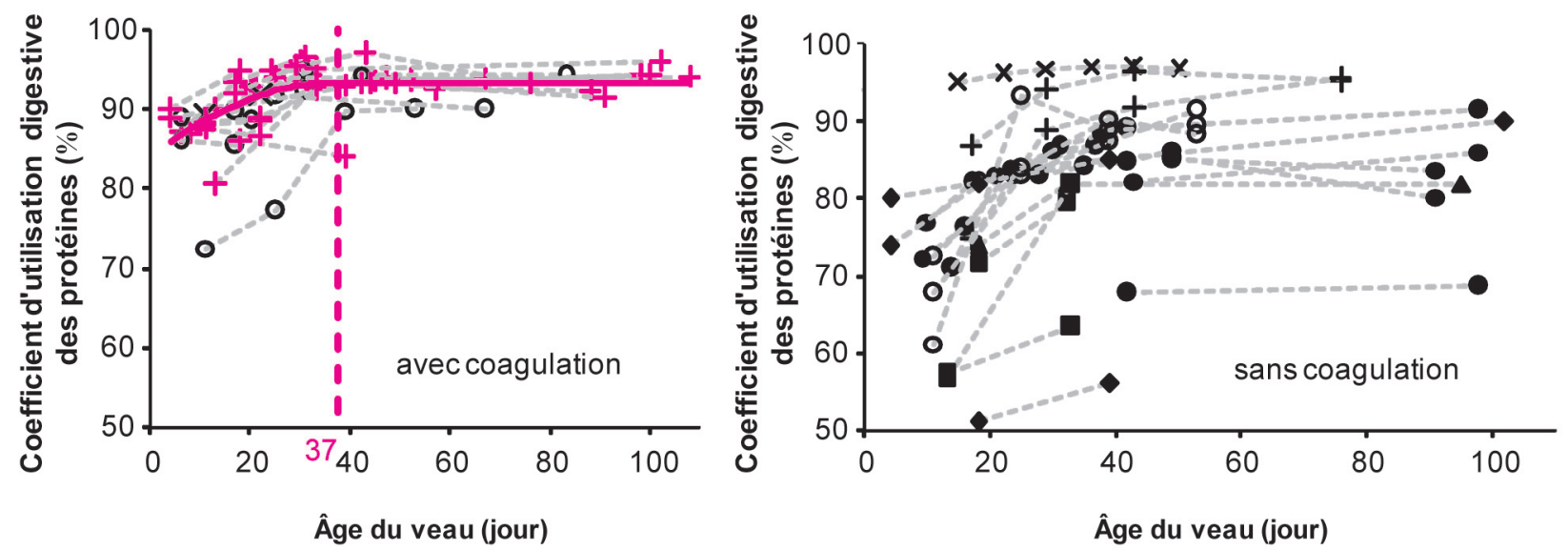

Les traits en pointillés relient les points d'un même essai. La courbe rouge représente l'évolution du coefficient d'utilisation digestive des protéines apportées par le lait écrémé ou la poudre de lait écrémé et coagulant dans la caillette ; le plateau (93\%) est atteint lorsque l'âge est supérieur à 37 jours.

des facteurs antinutritionnels (inhibiteurs d'enzymes, lectines, tannins) qui, lorsqu'ils sont insuffisamment inactivés par les processus technologiques pénalisent notamment la digestibilité des protéines (Huisman et Jansman 1991). Les farines et concentrats de soja par exemple sont généralement traités à la chaleur humide, à l'acide ou à l'alcool afin d'éliminer ces facteurs antinutritionnels. Le concentrat de soja traité à l'acide a cependant une digestibilité des protéines plus faible (70\%) que celui extrait à l'alcool $(88 \%$, tableau 2). De même, un isolat de protéines de soja hydrolysées présente une meilleure utilisation digestive des protéines qu'une farine de soja chauffée (90 vs $59 \%$, Lallès et al 1995) (tableau 2). Les protéines du gluten de blé présentent une digestibilité élevée, quel que soit le traitement technologique appliqué (en moyenne 93,5\%, Toullec et Grongnet 1990) (tableau 2).

\section{2 / Apports et digestion des lipides}

\section{1 / Les sources de matières grasses dans les aliments d'allai- tement}

Les MG représentent en moyenne $30 \%$ de la MS du lait entier et 18 à $22 \%$ de celle des aliments d'allaitement. Pour des raisons principalement économiques, les $\mathrm{MG}$ du lait sont utilisées préférentiellement dans l'industrie laitière pour l'alimentation humaine et sont généralement substituées dans les aliments d'allaitement par des graisses animales (suif, saindoux) ou par des MG végétales (huile de coprah, huile de palme).

\section{a) Les matières grasses d'origine lai-} tière

Les Acides Gras (AG) contenus dans le lait sont essentiellement sous forme de triglycérides (98\%), et sont constitués à $65 \%$ d'AG saturés. Les MG d'origine laitière présentent une très grande variété d'AG avec une proportion d'AG à chaîne courte plus élevée que les autres MG animales (15\% des AG totaux).

\section{b) Les matières grasses d'origine ani-} male

Après une période de moindre utilisation pour restriction réglementaire liée à la crise de l'ESB, le suif et le saindoux, bien que toujours soumis à une stricte réglementation de collecte et d'utilisation, sont les deux principales MG d'origine animale utilisées dans les aliments d'allaitement. Le suif se présente sous la forme de triglycéri- des riches en AG longs et saturés, particulièrement en acide stéarique $(15 \%$ des AG totaux du suif; Sauvant et al 2004) et possède également beaucoup d'AG insaturés comme l'acide oléique (46\% des AG totaux) et un peu d'acide linoléique (4\% des $A G$ totaux). Le saindoux est utilisé pour la structure particulière de ses triglycérides mixtes (acide palmitique préférentiellement en position interne) et présente un profil en AG semblable au suif.

c) Les matières grasses d'origine végétale

Les huiles végétales sont une source de MG couramment introduites dans les aliments d'allaitement et dont l'emploi s'est particulièrement répandu au moment de la crise de l'ESB. Les plus utilisées sont les huiles de palme et de coprah plutôt que les huiles d'arachide, de colza et soja riches en $A G$ polyinsaturés qui favorisent le développement d'une stéatose hépatique (Leplaix-Charlat et al 1996) et dont le bas point de fusion pénalise leur introduction dans les aliments d'allaitement. Ainsi, les huiles de palme et de coprah possèdent beaucoup plus d'AG saturés (52 et $57 \%$ des $\mathrm{AG}$ totaux respectivement) que les huiles d'arachide $(19,8 \%)$ et de colza $(7,6 \%)$. 


\section{2 / La digestion dans la caillet- te}

La salive du veau contient une lipase pharyngiale, l'estérase prégastrique, qui hydrolyse partiellement les triglycérides en diglycérides et AG libres dès leur arrivée dans la caillette (Guilloteau et al 1994, Toullec et Lallès 1995). Lorsque les protéines de l'aliment d'allaitement contiennent une proportion importante de caséines, leur coagulation avec la MG et les lipases facilite l'hydrolyse des lipides en augmentant leur temps de séjour dans la caillette, en contact avec la lipase salivaire à des conditions de $\mathrm{pH}$ plus favorables à l'action de l'enzyme à l'intérieur du coagulum ( $\mathrm{pH}$ d'environ 4,5). Le $\mathrm{pH}$ devient cependant rapidement inférieur à cette valeur à l'extérieur du coagulum (2,0 à 2,8 dans la phase liquide; Toullec et Lallès 1995). La lipase salivaire possède une double spécificité de position et de nature de chaîne permettant de libérer préférentiellement les $\mathrm{AG}$ à chaîne courte et moyenne (de 4 à 8 carbones) en position 3 dans les molécules de triglycérides. Ainsi, sous l'action de la lipase salivaire, plus de $65 \%$ des AG courts et moyens et $25 \%$ des $\mathrm{AG}$ longs du lait sont libérés dans la caillette (BrancoPardal et al 1995). La lipase agit également sur les chaînes aliphatiques courtes et moyennes des MG végétales (huile de coprah) et animales (suif, saindoux), libérant par exemple $24 \%$ des
AG du suif (Toullec et Felinski 1971). Globalement à la sortie de la caillette et dans un contexte de coagulation, les MG sont principalement des triglycérides (50 à 70\%), des diglycérides (10 à $25 \%$ ) et des AG non estérifiés, mais très peu de monoglycérides $(\leq 3 \%$; Toullec et Lallès 1995). Pour les aliments d'allaitement qui ne coagulent pas dans la caillette, la digestion des MG est donc limitée et se déroule principalement dans l'intestin grêle.

\section{3 / La digestion dans l'intestin grêle}

Dans l'intestin grêle, les sels biliaires émulsifient et solubilisent les lipides au niveau duodénal. L'action de la lipase, de la phospholipase et de la cholestérolestérase pancréatiques est favorisée par la formation de globules gras stabilisés. L'absorption intestinale des produits de l'hydrolyse des lipides est favorisée par la formation de micelles mixtes (Bauchart et Aurousseau 1993, Toullec et Lallès 1995). Le site de réaction est situé à l'interface huile-eau des globules gras, sur lesquels la lipase a la propriété de s'adsorber grâce à l'intervention de la colipase. De plus, le chyme acide est neutralisé par les bicarbonates du suc pancréatique et de la bile, ce qui rend le $\mathrm{pH}$ plus favorable à l'action des enzymes pancréatiques (Bauchart 1981, Marounek et al 2008). L'hydrolyse par la lipase pancréatique entraîne la libé- ration exclusive d'AG libres et de 2-monoglycérides, plus rapidement pour les AG à chaîne courte et moyenne que pour les AG à chaîne longue. Ainsi, les MG du lait, avec des triglycérides riches en AG courts et saturés ont une meilleure digestibilité $(96 \%)$ que celle du suif (90\%; Dimick et al 1965, Toullec et Mathieu 1969). L'hydrolyse serait similaire pour les AG polyinsaturés (Toullec et Mathieu 1969). Cependant, 1'utilisation digestive des MG d'aliment d'allaitement contenant des AG polyinsaturés (huile d'arachide, huile de soja, huile de colza), semble moins bonne et aboutit à des cas fréquents de diarrhée (Cottyn et al 1972) ce qui peut être amélioré par une hydrogénation partielle (Bakker et Veen 1969). Les phospholipides apportés par la bile et par les aliments sont partiellement hydrolysés en lysophospholipides sous l'action de la phospholipase $\mathrm{A}_{2}$, qui libère l'AG en position interne. Les esters de cholestérol sont hydrolysés par la cholestérol-estérase en cholestérol et AG non estérifiés (Toullec et Lallès 1995). Ces différents produits sont ensuite absorbés dans l'intestin grêle au niveau du jéjunum à l'exception des sels biliaires qui sont absorbés plus tardivement par l'iléon (partie terminale), assurant ainsi leur rôle solubilisant tout au long des sites d'absorption des lipides. La vitesse de l'hydrolyse des MG dans l'intestin est proportionnelle à la surface des globules et augmente avec la

Figure 2. Effet de l'âge du veau préruminant sur l'utilisation digestive des matières grasses de l'aliment d'allaitement.

Source de matières grasses :

+ : matière grasse laitière (Raven et Robinson 1958)

$x$ : saindoux (Toullec et Matthieu 1969)

+ : suif (Toullec et Matthieu 1969, Lallès et al 1995)

- : huile de palme (Toullec et Matthieu 1969)

- : huile de palme hydrogénée (Raven et Robinson 1958)

^ : huile de coprah (Toullec et Matthieu 1969)

$\checkmark$ : margarine (Roy et al 1970)

o : composition mixte (Nitsan et al 1972, Toullec et al 1974, Grongnet et al 1981, Akinyele et Harshbarger 1983, Ternouth et al 1985, Toullec et al 1994, Lallès et al 1995, Labussière et al 2009)
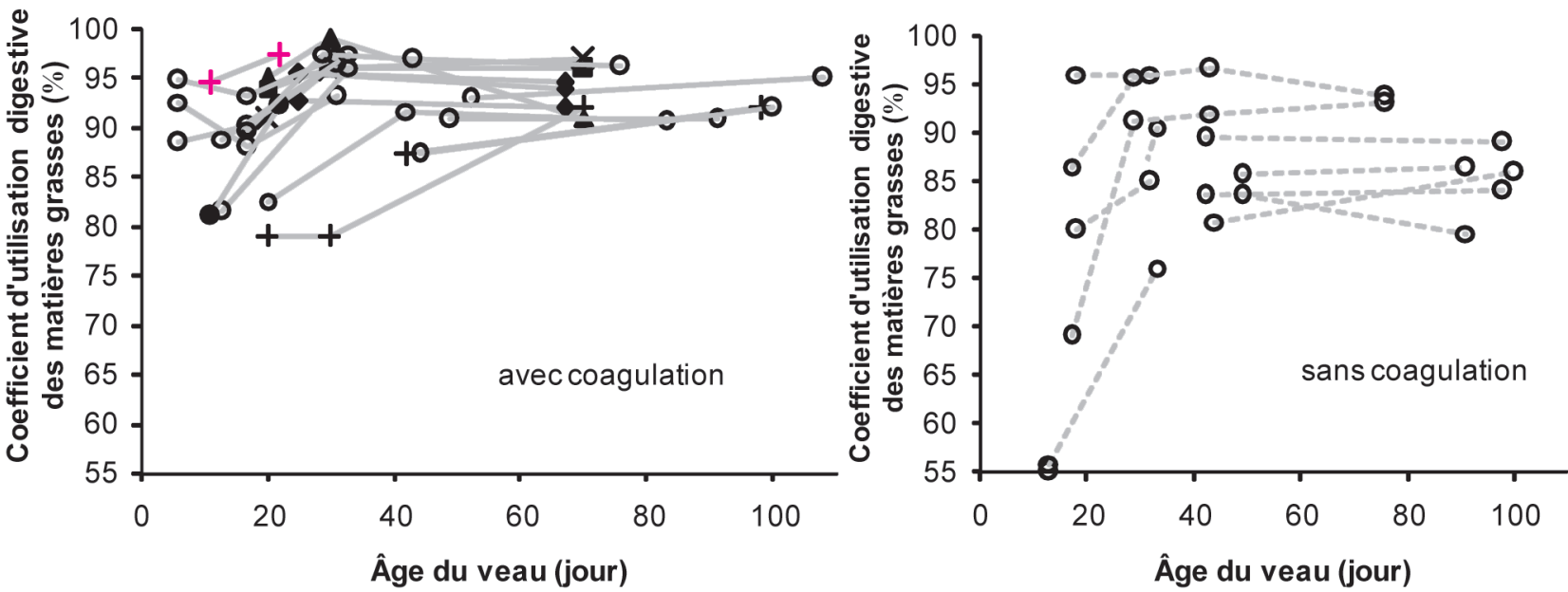

Les traits en continu relient les points d'un même essai et utilisant un aliment d'allaitement coagulant dans la caillette ; les traits en pointillés relient les points d'un même essai et utilisant un aliment qui ne coagule pas dans la caillette. 
finesse de l'émulsion (Toullec et Lallès 1995). En revanche, une teneur élevée en calcium dans l'aliment d'allaitement, modifie la qualité de l'émulsion et diminue la digestibilité des lipides (- 3 à 4 points, $\mathrm{Xu}$ et al 2000, Yuangklang et al 2004).

\section{4 / Les principaux facteurs de variation}

\section{a) L'âge du veau}

Chez le veau, la digestibilité des MG des huiles végétales (palme, coprah, margarine) ne varie pratiquement pas avec l'âge, alors que celle du suif et du saindoux augmente sensiblement entre la 3 ème et la 4 ème semaine d'âge (de 80 à $93 \%$ pour le suif et de 90 à $97 \%$ pour le saindoux) pour demeurer sensiblement constante ensuite (Toullec et Mathieu 1969) (figure 2). Cependant, cet effet semble plus important lorsque les protéines de l'aliment ne coagulent pas (Nitsan et al 1972). L'évolution de la digestibilité des MG pourrait être due à une sécrétion insuffisante de sels biliaires au début de la vie de l'animal (Toullec et Mathieu 1969), conjuguée à l'arrivée massive des MG dans le duodénum lorsqu'il n'y a pas de coagulum dans la caillette. Au-delà du premier mois de vie de l'animal, le coefficient d'utilisation digestive des MG ne semble pas varier, quelle que soit la composition des MG ou la cinétique digestive dans la caillette (figure 2).

\section{b) La présence ou non de coagulation}

La modification ou la suppression de la coagulation des protéines du lait par addition de citrate de sodium ou d'acide chlorhydrique diminue l'utilisation digestive des $M G$ du lait chez le veau jusqu'à l'âge d'un mois de 90 à $69 \%$ avec l'ajout d'acide chlorhydrique et de 90 à $77 \%$ avec l'ajout de citrate de sodium (Toullec et al 1974) (tableau 3). En revanche, la digestibilité des lipides du saindoux n'est pas modifiée lors de la suppression de la coagulation des protéines par ajout d'oxalate de sodium (Petit et al 1989) (tableau 3). Cependant, l'ajout d'un acide ou d'une base pour supprimer la coagulation dans la caillette peut également modifier l'efficacité des enzymes et pourrait expliquer les différences observées entre ces deux études. Toutefois, l'utilisation de protéines issues du soja, du blé et de la pomme de terre provoque également une réduction de la digestibilité apparente fécale des MG de l'ordre de 2 à 7 points (tableau 3 ). Cependant, cet effet pourrait également être lié à l'absence de phosphorylation des protéines végétales, pénalisant l'émulsion du contenu duodénal par piégeage des acides biliaires avec le phosphate de calcium (Xu et al 1997).

\section{c) La structure des acides gras}

La composition en AG (longueur de chaîne, degré d'insaturation et position dans le triglycéride) a une importance prépondérante sur l'utilisation digestive des MG par le veau (Toullec et Mathieu 1969), comme chez tous les monogastriques. Ainsi, les différences de digestibilité entre les AG d'une même MG sont d'autant plus fortes que la digestibilité apparente de la MG est faible (4\% entre les acides stéarique et linoléique dans le cas des MG du lait, 19\% dans le cas du suif) (Toullec et Mathieu 1969). L'activité différentielle de la lipase pancréatique en fonction de la longueur de chaîne favorise la digestibilité totale des AG courts (< C10; Toullec et Lallès, $1995)$ et génère des variations importantes dans le cas des AG longs. Ainsi, leur digestibilité dépend de la proportion d'AG courts ou insaturés qui les accompagnent : la digestibilité apparente de l'acide palmitique passe de $86 \%$ dans le suif $(35 \%$ d'AG insaturés et $4 \%$ d'AG $<$ C14) à $91 \%$ dans l'huile de coprah (10\% d'AG insaturés et $58 \%$ d'AG $<$ C14) et $92 \%$ dans l'huile de palme $(50 \%$ d'AG insaturés et $1 \%$ d'AG $<$ C14, Toullec et Mathieu 1969). Cela pourrait s'expliquer notamment par la solubilité micellaire plus grande des AG saturés par rapport aux AG insaturés (Hoffmann 1966, Savary 1966). Ainsi, l'utilisation du suif ou de mélanges d'huiles végétales, présentant la même teneur en AG saturés et insaturés ne modifie pas l'utilisation digestive des MG d'une ration constituée de $50 \%$ d'aliment solide et de $50 \%$ d'aliment d'allaitement (Huuskonen et al 2005).

La digestibilité des AG est également influencée par leur position au sein des triglycérides. En effet, les AG estérifiés en position interne sur la molécule possèdent une meilleure digestibilité que les AG en position externe (poulet: Renner et Hill 1961, rat: Vaique 2009). Ainsi, l'acide palmitique du saindoux qui est situé préférentiellement en position interne dans les molécules de triglycérides mixtes, a une digestibilité plus élevée $(95 \%)$ que celui de l'huile de palme, positionné préférentiellement en position externe (92\%; Toullec et Mathieu 1969).

\section{d) La quantité ingérée}

La digestibilité des MG diminue quand la quantité d'aliment ingérée augmente, surtout chez le jeune animal ( $<1$ mois d'âge) dont la maturation du pancréas n'est pas optimale. Ainsi, à quatre semaines d'âge, lorsque la quantité de lait entier consommée augmente de $60 \%$ ou de $90 \%$ (de 100 à 160 ou 190 g/kg de PV), la quantité de MG fécale est multipliée par deux ou huit, respectivement (Toullec et Mathieu
1971). L'augmentation de la teneur en MG de 14 à $24 \%$ diminue également l'utilisation digestive des lipides de 4 points chez des veaux âges de moins d'un mois (Hill et al 2009). Cependant le taux d'introduction de $\mathrm{MG}$ dans le régime n'aurait pas d'influence sur l'utilisation digestive des MG chez des veaux plus âgés. Ainsi, il n'y a aucune différence significative pour l'utilisation digestive du suif entre deux régimes à base de poudre de lait écrémé et avec une teneur en $\mathrm{MG}$ respective de 27 et $32 \%$ et pour un veau âgé de plus d'un mois $(94,4$ et $95,5 \%$; Toullec et Mathieu 1971).

e) La technologie d'incorporation dans l'aliment

Les MG peuvent être incorporées dans l'aliment par voie humide ou par voie sèche (Toullec et al 1977). La voie humide consiste à les homogénéiser avec du lait écrémé ou du lactosérum (parfois concentré) et un émulsifiant, et à sécher le mélange obtenu avec le procédé spray. Dans la voie sèche, elles sont pulvérisées sur un ou plusieurs autres ingrédients déjà sous forme de poudre. Ce type de procédé ne permet pas d'obtenir des particules aussi fines (8 à $12 \mu \mathrm{m}$, au lieu de 2 à $4 \mu \mathrm{m}$ ), ni des liaisons lipoprotéiques aussi développées. En conséquence, les MG incorporées dans l'aliment par la voie sèche sont moins digestibles $(87 \%$ pour le suif contre $90 \%$ par voie humide; tableau 3 ), surtout si elles sont riches en $A G$ longs saturés et en l'absence d'émulsifiant (Toullec et Lallès 1995). L'ajout d'émulsifiants dans l'aliment d'allaitement, tels que la lécithine de soja, les monoglycérides et les saccharoglycérides, a des effets positifs dans le cas de la voie sèche, mais n'augmente pas la digestibilité des MG dans le cas de la voie humide. De même, l'homogénéisation des MG dans l'aliment d'allaitement à basse pression augmente le coefficient d'utilisation digestive des lipides chez des veaux âgés de moins d'un mois, comparativement à une simple homogénéisation (Jenkins et al 1981).

\section{3 / Apports et digestion des glucides}

\section{1 / Les sources glucidiques dans les aliments d'allaitement}

\section{a) Le lactose}

Le lactose est le constituant majeur de la MS du lait (38\%) et la principale source de glucides des aliments d'allaitement (jusqu'à $50 \%$ de la MS). Il est souvent incorporé dans les aliments d'allaitement par l'intermédiaire de la 
Tableau 3. Facteurs de variation de l'utilisation digestive apparente fécale de différentes matières grasses par le veau préruminant.

\begin{tabular}{|c|c|c|c|c|c|c|}
\hline $\begin{array}{l}\text { Facteurs de } \\
\text { variation }\end{array}$ & $\begin{array}{l}\text { Sources } \\
\text { lipidiques }\end{array}$ & $\begin{array}{l}\text { Coagulation } \\
\text { (facteur anti- } \\
\text { coagulant) }\end{array}$ & $\begin{array}{c}\text { Taux } \\
\text { d'incorpora } \\
\text { tion des } \\
\text { lipides } \\
\text { (\% MS) }\end{array}$ & $\begin{array}{l}\text { Age des } \\
\text { veaux (j) }\end{array}$ & $\begin{array}{l}\text { Digestibilité } \\
\text { apparente } \\
\text { fécale des } \\
\mathrm{AG}^{(1)}(\%)\end{array}$ & Références \\
\hline \multirow{18}{*}{ Coagulation } & \multirow{2}{*}{$\begin{array}{l}\text { Matière grasse du } \\
\text { lait }\end{array}$} & $\begin{array}{c}\text { non (acide chlorhydrique } \\
\text { - citrate de sodium) }\end{array}$ & 20 & $<35$ & $69-77$ & \multirow{2}{*}{$\begin{array}{l}\text { Toullec et al } \\
\quad(1974)\end{array}$} \\
\hline & & oui & 20 & $<35$ & 90 & \\
\hline & \multirow{2}{*}{ Saindoux } & non (oxalate de sodium) & 20 & $<35$ & 89 & \multirow{2}{*}{ Petit et al (1989) } \\
\hline & & oui & 20 & $<35$ & 88 & \\
\hline & \multirow{2}{*}{ Mixte (> 93\% suif) } & $\begin{array}{l}\text { non (protéines de poids } \\
\text { ou de soja) }\end{array}$ & 19 & $70-135$ & 88 & \multirow{2}{*}{$\begin{array}{l}\text { Nunes Do Prado } \\
\text { et al (1989) }\end{array}$} \\
\hline & & oui & 19 & $70-135$ & 95 & \\
\hline & \multirow{2}{*}{ Mixte (> 93\% suif) } & non (protéines de soja) & 20 & $9-56$ & 84 & \multirow{2}{*}{$\begin{array}{l}\text { Toullec et al } \\
\quad(1994)\end{array}$} \\
\hline & & oui & 20 & $9-56$ & 91 & \\
\hline & \multirow{2}{*}{ Mixte (> $91 \%$ suif) } & $\begin{array}{l}\text { non (protéines de blé ou } \\
\text { de pomme de terre) }\end{array}$ & 20 & $56-97$ & 87 & \multirow{2}{*}{$\begin{array}{c}\text { Branco Pardal et } \\
\text { al (1995) }\end{array}$} \\
\hline & & oui & 20 & $56-97$ & 93 & \\
\hline & \multirow{2}{*}{ Mixte (> 93\% suif) } & non (protéines de soja) & 19 & $42-97$ & 87 & \multirow{2}{*}{$\begin{array}{l}\text { Lallès et al } \\
\quad(1995)\end{array}$} \\
\hline & & oui & 19 & $42-97$ & 90 & \\
\hline & \multirow{2}{*}{ Mixte (> $92 \%$ suif) } & non (protéines de soja) & 20 & $60-104$ & 87 & \multirow{2}{*}{$\begin{array}{l}\text { Tukur et al } \\
\quad(1995)\end{array}$} \\
\hline & & oui & 20 & $60-104$ & 94 & \\
\hline & \multirow{2}{*}{ Mixte (> $87 \%$ suif) } & non (protéines de blé) & 21 & $>84$ & 92 & \multirow{2}{*}{$\begin{array}{c}\text { Toullec et Formal } \\
\text { (1998) }\end{array}$} \\
\hline & & oui & 21 & $>84$ & 94 & \\
\hline & Mixte (57\% suif, & non (protéines de soja) & 22 & $49-154$ & 93 & \\
\hline & $\begin{array}{l}26 \% \text { saindoux et } \\
17 \% \text { d'huile de } \\
\text { coprah) }\end{array}$ & oui & 22 & $49-154$ & 96 & $\begin{array}{l}\text { Yuangklang et al } \\
\qquad(2004)\end{array}$ \\
\hline \multirow{5}{*}{$\begin{array}{l}\text { Caractéristiques } \\
\text { des lipides et } \\
\text { des AG }\end{array}$} & $\begin{array}{l}\text { AG à chaîne } \\
\text { moyenne }\end{array}$ & & & & & \multirow{5}{*}{$\begin{array}{c}\text { Toullec et } \\
\text { Mathieu (1969) }\end{array}$} \\
\hline & Huile de coprah & oui & 20 & $7-100$ & 96 & \\
\hline & AG longs & & & & & \\
\hline & Suif & oui & 20 & $7-100$ & 90 & \\
\hline & Huile d'arachide & oui & 20 & $7-100$ & 93 & \\
\hline \multirow{4}{*}{$\begin{array}{l}\text { Technologie } \\
\text { d'incorporation }\end{array}$} & \multirow{2}{*}{ Suif } & oui & $\begin{array}{l}20 \text { (voie } \\
\text { sèche) }\end{array}$ & $>35$ & 87 & \multirow{2}{*}{$\begin{array}{l}\text { Hamada et al } \\
\quad(1965)\end{array}$} \\
\hline & & oui & $\begin{array}{l}20 \text { (voie } \\
\text { humide) }\end{array}$ & $>35$ & 90 & \\
\hline & \multirow[t]{2}{*}{ Mixte (> $89 \%$ suif) } & oui & $\begin{array}{c}40 \\
\text { (homogénéi }\end{array}$ & $3-14$ & $73^{(2)}$ & \multirow[b]{2}{*}{$\begin{array}{l}\text { Jenkins et al } \\
\quad(1981)\end{array}$} \\
\hline & & oui & $\begin{array}{c}\text { sation) } \\
40 \\
\text { (dispersion } \\
\text { à basse } \\
\text { pression) }\end{array}$ & $3-14$ & $90^{(2)}$ & \\
\hline
\end{tabular}

(1) AG : Acides Gras.

(2) Pourcentage de triglycérides hydrolysés $4 \mathrm{~h}$ après le repas à la sortie de l'intestin grêle.

poudre de lactosérum dont la teneur en lactose est d'environ $75 \%$ de la MS (tableau 1).

\section{b) Les amidons}

L'amidon est une molécule de réserve énergétique que l'on retrouve dans les végétaux comme les céréales (blé, riz, maiis), les tubercules (pomme de terre, manioc) ou encore dans les légumineuses (pois). Il peut être incorporé brut dans les aliments d'allaitement ou sous différentes formes plus ou moins traitées (amidon préhydrolysé, amidon pré- gélatinisé) afin d'améliorer sa digestibilité.

c) Les maltodextrines et les dextrines

Les dextrines et les maltodextrines sont des chaînes de glucides solubles 
(glucose, maltose, maltotriose, oligosides et polyosides) et amorphes. Elles sont obtenues par dessiccation ou hydrolyse acide de l'amidon (blé, maïs, pomme de terre).

\section{2/ La digestion dans la caillette}

La salive et les sécrétions gastriques étant dépourvues d'enzymes glycolytiques, les glucides sont très peu attaqués dans la caillette (Toullec et Lallès 1995). De plus, le lactose, ainsi que les autres glucides solubles, séjournent beaucoup moins longtemps dans la caillette que le coagulum des protéines et des MG. Chez le veau nourri au lait, les quantités de substances réductrices ayant quitté la caillette représentent $44 \%$ de la quantité ingérée une heure et demie après le repas (Guilloteau et al 1975) et environ $72 \%$ de la quantité ingérée sept heures après le repas (Mylrea 1966, Mathieu 1968). A l'in- verse, l'amidon est évacué lentement car il est retenu dans le coagulum lorsque des caséines sont présentes en quantité suffisante (Coombe et Smith 1974). Ainsi, l'emploi de protéines de substitution ne modifie pas notablement la vitesse d'évacuation gastrique du lactose, mais accélère probablement celle de l'amidon. L'acide chlorhydrique sécrété dans la caillette rompt les liaisons hydrogènes dans les zones amorphes de l'amidon bien que ce phénomène ne semble pas faciliter l'attaque ultérieure des enzymes pancréatiques, au moins dans le cas de l'amidon de maïs (Toullec et Lallès 1995).

\section{3 / La digestion dans l'intestin grêle}

Les glucides simples, dont les sucres constitutifs sont liés par des liaisons $\alpha(1-4)$, sont hydrolysés dans l'intestin grêle par les enzymes contenus dans le suc intestinal et le suc pancréatique comme le lactose par la lactase (Besle 1985). Le $\mathrm{pH}$ optimum de la lactase est de $6,5, \mathrm{pH}$ proche de celui du contenu digestif de la première moitié du jéjunum (pH 6,8) (Guilloteau 1986, Yvon et al 1986). Les produits libérés sont des sucres simples (glucose, galactose) facilement absorbables (Lallès et Poncet 1986). Les sucres totaux échappant à la digestion dans l'intestin grêle représentent environ $2,5 \%$ du lactose ingéré chez le veau nourri au lait (Besle et al 1983). La digestion apparente du lactose est donc quasiment totale $(99 \%$; Toullec et Lallès 1995) (tableau 4). Huber et Moore (1964) ont néanmoins montré qu'une ingestion de $20 \mathrm{~g}$ de lactose $/ \mathrm{kg}$ PV et par jour provoque des diarrhées, déterminées par la formation importante d'acides organiques (acétique et lactique principalement) dans le caecum et le colon. De plus, l'ingestion d'environ $80 \%$ de l'apport journalier de

Tableau 4. Facteurs de variation de l'utilisation digestive apparente fécale de différentes sources glucidiques par le veau préruminant.

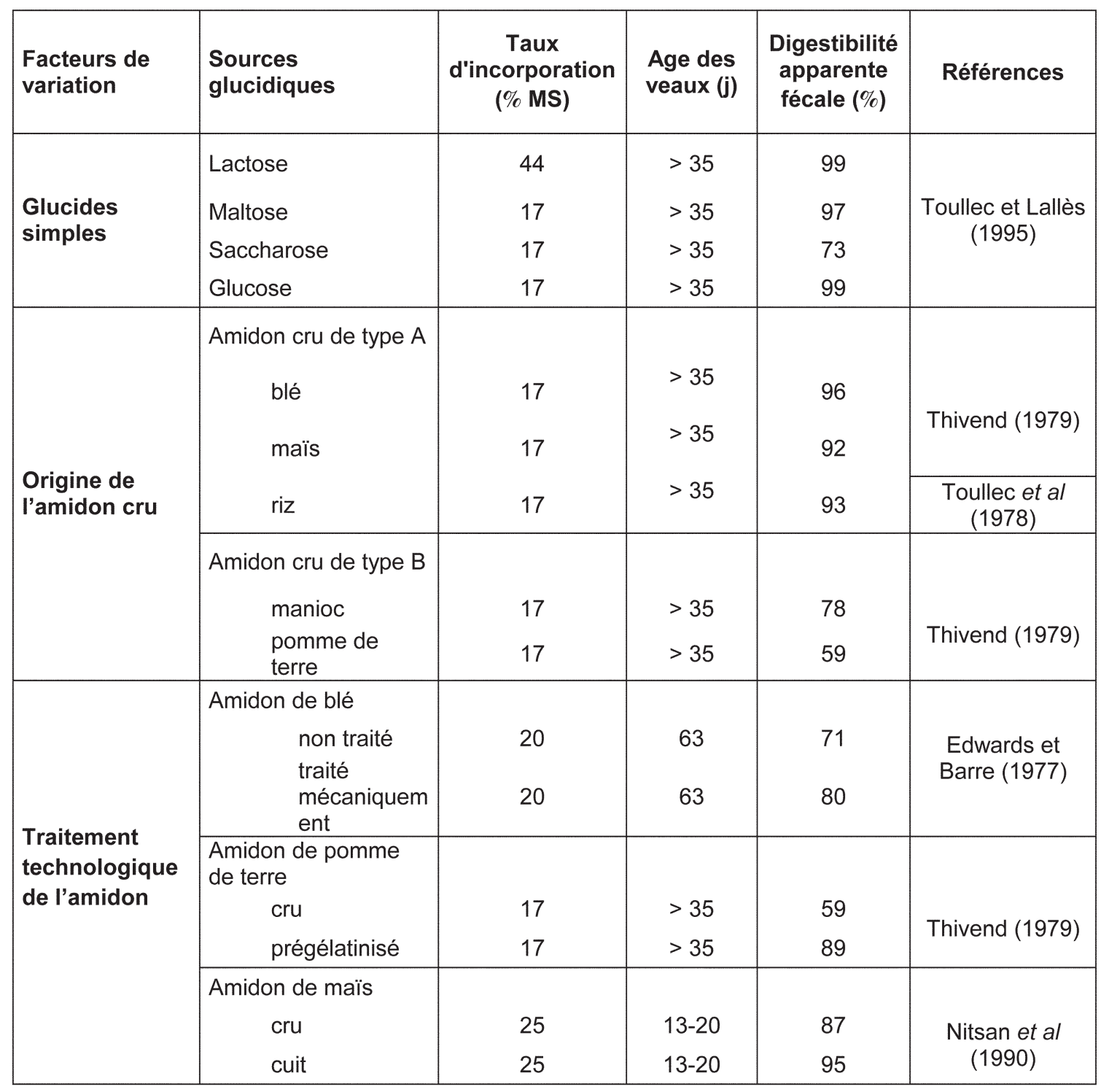


lactose (6 g/kg PV et par jour) en un seul repas avec une teneur réduite en protéines provoque également des diarrhées et diminue la digestibilité du lactose de 22 points (van den Borne et al 2006). Cela serait dû à une saturation des systèmes de transport du glucose et surtout du galactose dans l'intestin grêle. Cependant, le lactose est en moyenne introduit à raison de $8 \mathrm{~g} / \mathrm{kg}$ $\mathrm{PV} / \mathrm{j}$ en deux repas dans la ration d'un veau de boucherie (soit environ 50\% de la MS de l'aliment d'allaitement); ce phénomène ne se rencontre donc pas dans des situations conventionnelles d'élevage.

La digestion des glucides complexes comme l'amidon ou les dextrines nécessite l'action de plusieurs enzymes comme l'amylase contenue dans le suc pancréatique, et la maltase et l'isomaltase présentes au niveau de la membrane des entérocytes (Montagne 2000). L'amylase pancréatique est une $\alpha$-amylase catalysant l'hydrolyse des liaisons $\alpha$ (1-4) à l'intérieur des polymères de glucose, sauf celles adjacentes à une liaison $\alpha$ (1-6). Son $\mathrm{pH}$ optimal d'activité est de l'ordre de 6,7 à 7,0 (Peyraud 1983, Toullec et Lallès 1995), ce qui correspond au $\mathrm{pH}$ du contenu digestif dans l'intestin grêle (Guilloteau 1986, Yvon et al 1986). Les produits de cette hydrolyse rapide sont le maltose, le maltotriose et le maltotétraose. Le maltotétraose est ensuite scindé en maltose, tandis que le maltotriose n'est hydrolysé que très lentement. L'amylopectine fournit aussi du maltose et du maltotriose, mais également des dextrines comprenant une ou deux liaisons $\alpha$ (1-6). Les oligosaccharides produits sont hydrolysés au niveau de la membrane des entérocytes par la maltase et l'isomaltase, dont la partie hydrophile fonctionnelle est située à l'extérieur de la membrane plasmique. La maltase attaque les liaisons $\alpha$ (1-4) à l'extrémité non réductrice des oligosaccharides et l'isomaltase attaque les liaisons $\alpha$ (16) des dextrines et de l'isomaltose (Peyraud 1983, Toullec et Lallès 1995). Finalement, la digestion de l'amidon produit des glucides simples facilement assimilables par le veau. La digestibilité des amidons diminue cependant quand le taux d'introduction augmente. Ainsi, la digestibilité apparente des amidons de manioc, de maïs ou de pomme de terre diminue de 9 à 33 points quand le taux d'introduction augmente de 17 à 44\% de la MS (Mathieu et Thivend 1968). De même, la digestibilité appa-

Figure 3. Effet de l'âge du veau préruminant sur l'utilisation digestive des glucides de l'aliment d'allaitement.

Source de glucides :

+ : lactose (Raven et Robinson 1958, Roy et al 1970, Ternouth et al 1985, Dawson et al 1988)

- : amidon de manioc (Mathieu et Toullec 1968, Assan 1974)

^ : amidon de blé (Edwards et Barre 1977, Thivend 1979)

- : amidon de maïs (Raven et Robinson 1958, Mathieu 1968, Edwards et Barre 1977)

: amidon de maïs éclaté (Mathieu et Toullec 1968)

o : composition mixte (Dawson et al 1988, Grongnet et al 1981, Toullec et al 1994, Lallès et al 1995)

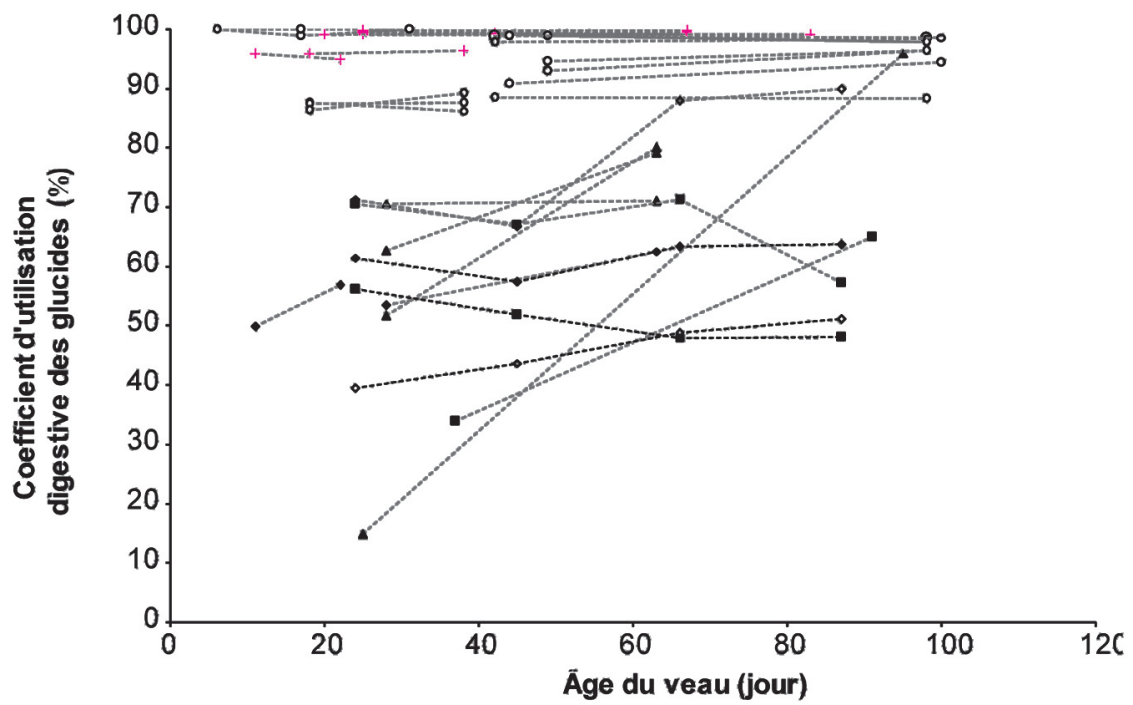

Les traits en pointillés relient les points d'un même essai. Pour les amidons, les pointillés gris indiquent un taux d'introduction de l'amidon de 17 à $26 \%$, les pointillés noirs indiquent un taux d'introduction de l'amidon de $44 \%$. rente des dextrines de maïs ou de pomme de terre et de la maltodextrine diminuent respectivement de 92 à $66 \%$, de 86 à $49 \%$ et de 80 à $67 \%$ lorsque le taux d'introduction augmente de 25 à $75 \mathrm{~g} / \mathrm{kg}$ de lait liquide ingéré (Mathieu et al 1970).

Les autres glucides (saccharose, $\alpha$ galactosides, cellulose et hémicelluloses) ne sont pas attaqués en raison d'un équipement enzymatique déficient en enzymes glycolytiques de type $\beta$ (Guilloteau et al 1995). Ainsi, plus de $90 \%$ du saccharose échappe à la digestion dans l'intestin grêle lorsqu'il est infusé directement dans le duodénum du jeune veau, à raison de 30,60 ou $90 \mathrm{~g} / \mathrm{j}$ (Chongo et Thivend 1982). Il en résulte un appel croissant d'eau dans la lumière intestinale induisant rapidement une diarrhée osmotique (Mathieu et Barré 1968). La digestion du saccharose se déroule essentiellement par fermentation dans le gros intestin. Au niveau fécal, la digestibilité du saccharose est de $73 \%$ (Toullec et Lallès 1995) (tableau 4). De même, seulement 30\% de la cellulose et des hémicelluloses sont digérés dans l'intestin grêle chez le veau nourri avec un aliment contenant $30 \%$ de concentrats de soja (Guilloteau et al 1986). La digestion de ces glucides résulte principalement des fermentations microbiennes dans le gros intestin (Mathieu et Barré 1968, Juhász et al 1976, Guilloteau et al 1986, Toullec et Lallès 1995). Cependant, les glucides pariétaux sont généralement peu présents dans les aliments d'allaitement. Ils ne sont apportés que par les sources de protéines végétales, dont les teneurs en glucides n'excèdent pas $8 \%$ et dont les taux d'introduction dans les aliments d'allaitement sont limités.

\section{4 / Les principaux facteurs de variation}

\section{a) L'âge du veau}

La digestibilité du lactose ne semble pas être affectée par l'âge chez le veau de boucherie (figure 3). En revanche, l'âge de l'animal est un facteur de variation de la digestion des autres glucides durant les deux premiers mois de vie de l'animal (Ternouth et al 1976, Guilloteau 1986). Ainsi, chez le veau, la digestibilité de l'amidon de manioc (introduit à $17 \%$ de la MS) passe de $34 \%$ à $65 \%$ entre les âges de 37 et 91 jours (Assan 1974) (figure 3). De même, la digestibilité de l'amidon de blé cru (introduit à $17 \%$ de la MS) passe de $15 \%$ à $96 \%$ entre les âges de 19 et 89 jours (Thivend 1979). La digestibilité de l'amidon de maïs évolue également avec l'âge, au moins jusque 60 jours d'âge (figure 3). Ces évolutions de digestibilité sont la conséquence d'une 
maturation du pancréas au cours des deux premiers mois de vie du veau qui se traduit par la production accrue d'amylase et sa sécrétion dans la lumière de l'intestin grêle. Ainsi, 12 heures après l'ingestion du repas, la quantité d'amylase sécrétée évolue de 180 à 780 puis à $2690 \mathrm{mg} / \mathrm{kg}$ PV pour des âges respectifs de 7, 24 et 63 jours pour ne plus évoluer ensuite (Ternouth et al 1976).

\section{b) L'origine botanique des glucides}

L'aptitude du veau préruminant à digérer les glucides par voie enzymatique est plus limitée pour les produits amylacés que pour le lactose (Coombe et Smith 1974). Les polymères de glucides, en particulier les amidons, diffractent les rayons $\mathrm{X}$ selon leur forme et leur degré de ramification et peuvent, selon la forme du spectre obtenu, se classer en type A pour les amidons de céréales, type B pour les amidons de tubercules ou type $\mathrm{C}$, intermédiaire entre les types A et B, pour les amidons de plusieurs légumineuses (Duprat et al 1980). Ainsi, la digestibilité apparente des amidons de type A est plus élevée (blé : $96 \%$, riz : $93 \%$ et maïs : $92 \%$ ) que celle des amidons de type B (manioc: $78 \%$ et pomme de terre : $59 \%$ ) (tableau 4). Cette différence est due à une proportion plus importante d'amylopectine (plus facilement hydrolysée) dans l'amidon des céréales que dans celui des tubercules (Assan 1974, Thivend 1979). De manière générale, la digestion de l'amidon est d'autant plus rapide que la proportion d'amylopectine est importante et celle d'amylose est faible car la configuration hélicoïdale de l'amylose ne favorise pas la spécificité d'action de l'amylase (Toullec et Lallès 1995).

\section{c) Les traitements technologiques}

Les principaux traitements appliqués aux sources glucidiques sont de type hydrothermique (gélatinisation, floconnage, dextrinisation, hydrolyse partielle). Ils sont destinés à obtenir des propriétés physicochimiques particulières et à augmenter leur digestibilité en éliminant ou inactivant également certains facteurs antinutritionnels comme les $\alpha$-galactosides des protéagineux. Les traitements hydrothermiques provoquant la gélatinisation de l'amidon augmentent sa digestibilité chez le veau préruminant (Mathieu et Thivend 1968, Besle et al 1981). Ainsi l'amidon de pomme de terre prégélatinisé est mieux digéré $(89 \%)$ par le veau préruminant que l'amidon de pomme de terre cru (59\%) (Thivend 1979). L'utilisation digestive de l'amidon de maïs est également améliorée par la cuisson ( +8 points ; Nitsan et al 1990) (tableau 4). Enfin, un traitement mécanique de l'amidon de blé suffit à augmenter sa digestibilité de 9 points (Edwards et Barre 1977).

\section{Conclusion}

L'essentiel des nutriments nécessaires pour couvrir les besoins nutritionnels du veau préruminant est apporté par l'aliment d'allaitement formulé à base de diverses matières premières aussi bien animales que végétales. Cette synthèse bibliographique montre que les matières premières d'origine laitière (poudre de lait écrémé, poudre de lactosérum, lactose) sont en général très bien digérées par le veau préruminant avec des coefficients d'utilisation digestive apparente supérieurs à $90 \%$ pour les différents nutriments. Les autres matières premières ont une utilisation digestive plus variable qui dépend beaucoup de leurs origines et des traitements technologiques qui leur sont appliqués. Ainsi, leur utilisation digestive est plus contrastée, particulièrement chez l'animal jeune et recevant un aliment d'allaitement ne coagulant pas dans la caillette. L'emploi d'aliment d'allaitement formulé à base de poudre de lait écrémé riche en caséines est surtout préconisé durant la phase dite de «démarrage» en élevage de veau de boucherie, c'est-àdire durant le premier mois d'engraissement alors que l'appareil digestif du veau est encore immature pour digérer avec efficacité les autres sources de nutriments. Les valeurs de digestibilité rapportées dans la bibliographie, bien que relativement anciennes indiquent que le recours à des matières premières végétales est une alternative intéressante pour l'alimentation des veaux de boucherie, dans un contexte mondial de carence au niveau des produits animaux.

\section{Références}

Akinyele I.O., Harshbarger K.E., 1983. Performance of young calves fed soybean protein replacers. J. Dairy Sci., 66, 825-832.

Assan B.E., 1974. Contribution à l'étude de la digestion intestinale de l'amidon chez le veau préruminant. Thèse de Docteur Ingénieur, Université de Clermont Ferrand, France, 91p.

Bakker I.J.T., Veen W.A.G., 1969. L'usage de l'huile de baleine, sélectivement hydrogénée comme constituant d'un lait d'allaitement pour veaux à l'engrais. (De bruikbaarheid van selectief geharde visolie als bestanddeel van een kunstmelkpreparaat voor mestkalveren). Rapport annuel, Institut pour l'Alimentation Animale «De Schothorst», the Nederlands, 63-68.

Bauchart D., 1981. Digestion comparée des lipides chez les ruminants et les monogastriques. Bull. Tech. CRZV Theix, France, 46, 45-55.

Bauchart D., Aurousseau B., 1993. Digestion et métabolisme des lipides chez le veau de boucherie ; conséquences sur la composition en lipides des tissus. Viandes et Produits Carnés, 12, 172-182.

Besle J.M., 1985. Etude biochimique et physiologique de la digestion de différents glu- cides chez le veau préruminant. Thèse de Doctorat d'Etat, Université de ClermontFerrand II, France, 135-136.

Besle J.M., Lassalas B., Thivend P., 1981. Digestion des glucides cytoplasmiques de la féverole par le veau préruminant. Reprod. Nutr. Dev., 21, 629-649.

Besle J.M., Pougheon M., Bayle E., Thivend P., 1983. Etude des glucides totaux et des glycoprotéines endogènes des contenus intestinaux chez le veau préruminant. Reprod. Nutr. Dev., 23, 25-39.

Branco-Pardal P., Lallès J.P., Formal M., Guilloteau P., Toullec R., 1995. Digestion of wheat gluten and potato protein by the preruminant calf: digestibility, amino acid composition and immunoreactive proteins in ileal digesta. Reprod. Nutr. Dev., 35, 639-654.

Carlson A., Hill C.G. Jr., Olson N.F., 1987. Kinetics of milk coagulation. 1. The kinetics of kappa casein hydrolysis in the presence of enzyme deactivation. Biotechnol. Bioeng., 29, 582-589.

Caugant I., 1993. Digestion gastrique et intestinale de protéines laitières et végétales chez le veau préruminant: Etudes in vivo et in vitro. Thèse de Docteur Ingénieur, ENSAR, Rennes, France, 188p.

Caugant I., Toullec R., Formal M., Guilloteau P., Savoie L., 1993. Digestibility and amino acid composition of digesta at the end of the ileum in preruminant calves fed soyabean protein. Reprod. Nutr. Dev., 33, 335 347.

Chongo B., Thivend P., 1982. Digestion of final molasses carbohydrates in the small intestine of pre-ruminant calves. Cuban J. Agric. Sci., 16, 285-292.

Coombe N.B., Smith R.H., 1974. Digestion and absorption of starch, maltose and lactose by the preruminant calf. Brit. J. Nutr., 31, 227 235.

Cottyn B.G., Casteels M.R., Meskens P.R., Buysse F.X., 1972. Matières grasses végétales et animales dans les aliments d'allaitement pour veaux à l'engrais. Ann. Zootech., 21, 207222.

Dardillat C., Marrero E., 1977. Etude de l'électromyogramme global chronique de la paroi intestinale du veau préruminant : migration 
des phases d'activité régulière et relation avec le transit. Ann. Biol. Anim. Bioch. Bioph., 17, 523-530

Dawson D.P., Morrill J.L., Reddy P.G., Minocha H.C., Ramsey H.A., 1988. Soy protein concentrate and heated soy flours as protein sources in milk replacer for preruminant calves. J. Dairy Sci., 71, 1301-1309.

Diaz M.C., Van Amburgh M.E., Smith J.M., Kelsey J.M., Hutten E.L., 2001. Composition of growth of Holstein calves fed milk replacer from birth to 105-kilogram body weight. J. Dairy Sci., 84, 830-842.

Dimick P.S., McCarthy R.D., Patton S., 1965. Structure and synthesis of milk fat. 8 . Unique positioning of palmitic acid in milk fat triglycerides. J. Dairy Sci., 48, 735-737.

Duprat F., Gallant D., Guilbot A., Mercier C., Robin J.P., 1980. L'amidon. In : Les polymères végétaux. Polymères pariétaux et alimentaires non azotés. Monties B. (Ed). Gauthier-Villars, Paris, France, 176-231.

Edwards D.G., Barre P., 1977. The digestibility of wheat starch and maize starch by the pre-ruminant calf. Proc. Nutr. Soc., 36, $144 \mathrm{~A}$.

Faichney G.J., 1983. The effect of physical form of lucerne hay on the passage of markers through the rumen of sheep. Proc. Nutr. Soc. Austr., 8, 186-187.

Grongnet J.F., Patureau-Mirand P., Toullec R., Prugnaud J., 1981. Utilisation des protéines du lait et du lactoserum par le jeune veau préruminant. Influence de l'âge et de la dénaturation des protéines du lactosérum. Ann. Zootech., 30, 443-464.

Guilhermet R., Mathieu C.M., Toullec R. 1975. Transit des aliments liquides au niveau de la gouttière œsophagienne chez le veau préruminant et ruminant. Ann. Zootech., 24, 6979

Guilloteau P., 1986. Digestion des protéines chez le veau préruminant. Thèse de Doctorat, Université Pierre et Marie Curie Paris VI, Paris, France, 224p.

Guilloteau P., Paruelle J.L., Toullec R. Mathieu C.M., 1975. Utilisation des protéines par le veau préruminant à l'engrais. 3. Influence du remplacement des protéines du lait par celles du poisson sur la vidange stomacale. Ann. Zootech., 24, 243-253.

Guilloteau P., Toullec R., Sauvant D., Paruelle J.L., 1979. Utilisation des protéines par le veau préruminant à l'engrais. 7 . Influence du remplacement des protéines du lait par celles du soja ou de la fèverole sur l'évacuation gastrique. Ann. Zootech., 28, 1-17.

Guilloteau P., Toullec R., Garnot P., Martin P., Brulé G., 1980. Influence de l'âge sur les sécrétions de suc gastrique et d'électrolytes chez le veau préruminant. Reprod. Nutr. Dev., 20, 1279-1284.

Guilloteau P., Toullec R., Grongnet J.F. Patureau-Mirand P., Prugnaud J., Sauvant D., 1986. Digestion of milk, fish and soya-bean protein in the preruminant calf : flow of digesta, apparent digestibility at the end of the ileum and amino acid composition of ileal digesta. Brit. J. Nutr., 55, 571-592.

Guilloteau P., Chayvialle J. A., Le HuerouLuron I., Mouats A., Durand D., Bernard C. Bauchart D., Toullec R., 1994. Molecular forms, gastro-entero-pancreatic production and hepatic clearance of gastrin and somatostatin in the preruminant calf. Proc. Soc. Nutr. Physiol., 3, 294.

Guilloteau P., Le Hüerou I., Malbert C.H., Toullec R., 1995. Les sécrétions digestives et leur régulation. In : Nutrition des ruminants domestiques : ingestion et digestion. Jarrige $\mathrm{R}$. Ruckebusch Y., Demarquilly C., Farce M.H. Journet M. (Eds). INRA Editions, Paris, France, 490-527.

Guilloteau P., Plodari M., Romé V., Savary G., Le Normand L., Zabielski R., 2011. Pancreatic enzyme deficiency depends on dietary protein origin in milk-fed calves. J. Dairy Sci., 94, 1517-1525.

Hamada T., Kameoka K., Morimoto M. 1965. Studies on substitute milk containing dried skimmilk with tallow, lecithin or whea for dairy calves. Agric. Biol. Chem., 29, 998 1003

Henschel M.J., 1973. Comparaison of the developpement of proteolytic activity in the abomasum of the preruminant calf with that in the stomach of the young rabbit and guineapig. Brit. J. Nutr., 30, 285-296.

Hill T.M., Bateman II H.G., Aldrich J.M., Schlotterbeck R.L., 2009. Effects of fat concentration of a high-protein milk replacer on calf performance. J. Dairy Sci., 92, 5147-5153.

Hoffmann A.F., 1966. A physicochemical approach to the intraluminal phase of fat absorption. Gastroenterol., 50, 56-64.

Huber J.T., 1975. Fish Protein Concentrate and Fish Meal in Calf Milk Replacers. J. Dairy Sci., 58, 441-447.

Huber J.T., Moore W.E.C., 1964. Shortchain fatty acid concentrations posterior to the stomach of calves fed normal and milk diets. J. Dairy Sci., 47, 1421-1423.

Huisman J., Jansman A.J.M., 1991. Dietary effects and some analytical aspects of antinutritional factors in peas (Pisum sativum), common beans (Phaseolus vulgaris) and soyabeans (Glycine max L.) in monogastric farm animals. A literature review. Nutr. Abstr. Rev., 60, 901921.

Huuskonen A., Khalili H., Kiljala J., JokiTokola E., Nousiainen J., 2005. Effects of vegetable fats versus lard in milk replacers on feed intake, digestibility, and growth in Finnish Ayrshire bull calves. J. Dairy Sci., 88, 3575 3581

Jeantet R., Croguennec T., Mahaut M., Schuck P., Brulé G., 2008. Les produits laitiers 2 ème édition. Tec et Doc, Paris, France, $185 \mathrm{p}$.

Jenkins K.J., Kramer J.K.G., Emmons D.B 1981. Digestion of fat in calves fed milk replacers prepared by homogenization or lowpressure dispersion. J. Dairy Sci., 64, 19651971.

Juhász B., Szegedi B., Keresztes M., 1976 The abomasal digestion in calves during development of the forestomachs. Acta. Vet. Acad. Sci. Hung., 26, 281-295.

Kandra L., Gyemant G., 2000. Examination of the active sites of human salivary alphaamylase (HSA). Carbohyd. Res., 329, 579-585.

Labussière E., 2008. Besoins protéiques et énergétiques du veau de boucherie mâle de race Prim'Holstein. Thèse de Doctorat, Agrocampus Ouest, Rennes, 218p.

Labussière E., Maxin G., Dubois, S., van Milgen J., Bertrand G., Noblet J., 2009. Effect of feed intake on heat production and protein and fat deposition in milk-fed veal calves. Animal, 3, 557-567.

Lallès J.P., 1988. Etude de la digestion, du transit digestif et de quelques paramètres métaboliques et immunologiques chez le veau au cours du sevrage, dans le cas de deux rations différant par la nature des protéines de l'aliment concentré (pois ou tourteau de soja). Thèse de Doctorat, ENSAR, Rennes, 157p.

Lallès J.P., Poncet C., 1986. Utilisation comparée des particules colorées et des terres rares pour mesurer la vitesse de passage des résidus alimentaires dans le tube digestif du mouton. Reprod. Nutr. Dev., 26, 319-320.

Lallès J.P., Toullec R., Bouchez P., Roger L., 1995. Antigenicity and digestive utilization of four soya products by the preruminant calf. Livest. Prod. Sci., 41, 29-38.

Le Hüerou I., Guilloteau P., Puigserver A., Toullec R., Wicker C., 1990. Effects of age and weaning on the enzyme activities of abomasum, pancreas and intestine in the calf. Reprod. Nutr. Dev., 30, 132.

Leplaix-Charlat L., Durand D., Chilliard Y., Williams P., Bauchart D., 1996. Effects of diets containing tallow and soybean oil with and without cholesterol on hepatic metabolism of lipids and lipoproteins in the preruminant calf. J. Dairy Sci., 79, 1826-1835.

Marounek M., Dušková D., Savka O.G. Vyborná A., 2008. A note on distribution of lipolytic activity in the digestive tract of veal calves. J. Anim. Feed Sci., 17, 166-170.

Martin P., Collin J.C., Garnot P., RibadeauDumas B., Mocquot G., 1981. Evaluation of bovine rennets in terms of absolute concentrations of chymosin and pepsin. J. Dairy Res., 48, 447-456

Martin P., Trieu-Cuot P., Collin J.C., Ribadeau-Dumas B., 1982. Purification and characterization of bovine gastriscin. Eur. J. Biochem., 122, 31-39.

Mathieu C.M., 1968. Etude de la vidange stomacale du lait entier chez le veau préruminant. Ann. Biol. Anim. Bioch. Bioph., 8, 581583.

Mathieu C.M., Barré P.E., 1968. Digestion et utilisation des aliments d'allaitement par le veau préruminant à l'engrais. 4. Remplacement des matières grasses du lait par du sacharrose. Ann. Biol. Anim. Bioch. Bioph., 8, 501-515.

Mathieu C.M., Thivend P., 1968. Digestion et utilisation des aliments par le veau préruminant à l'engrais. 3. Remplacement des matières grasses du lait par différents amidons. Ann. Biol. Anim. Bioch. Bioph., 8, 249-271.

Mathieu C.M., Thivend P., Barré P.E., 1970. Digestion et utilisation des aliments par le veau préruminant à l'engrais. 5. Remplacement des matières grasses du lait par des dextrines. Ann. Biol. Anim. Bioch. Bioph., 10, 253-269.

Miller J.K., Perry S.C., Chandler P.T. Cragle R. G., 1967. Evaluation of radiocerium as a nonabsorbed reference material for determining gastrointestinal sites of nutrient absorption and excretion in cattle. J. Dairy Sci., 50, 355-361.

Miyazaki T., Miyazaki M., Yasuda J., Okada K., 2009. Ultrasonographic imaging of abomasal curd in preruminant calves. Vet. J., 179, 109-116.

Montagne L., 2000. Effets des matières azotées alimentaires sur les matières azotées endo- 
gènes, les mucines et la muqueuse de l'intestin grêle du veau préruminant. Thèse de Doctorat, ENSAR, Rennes, France, 198p.

Mylrea P.J., 1966. Digestion of milk in young calves. 2. The absorption of nutrients from the small intestine. Res. Vet. Sci., 7, 394406.

Neergaard L., 1979. Influence of specially extracted soya meal on nitrogen and energy metabolism in the preruminant calf. In: $8^{\text {th }}$ Symposium on Energy Metabolism. Mount L.E. (Ed). Butterworths, London, United Kingdom, 43.

Nitsan Z., Volcani R., Hasdai A., Gordin S., 1972. Soybean protein substitute for milk protein in milk for suckling calves. J. Dairy Sci., $55,811-821$.

Nitsan Z., Ben-Asher A., Nir I., Zoref Z., 1990. Utilization of raw or heat-treated starch fed in liquid diet to pre-ruminants. 1. Calves. Reprod. Nutr. Dev., 30, 507-514.

Nunes Do Prado I., Toullec R., Lallès J.P., Gueguen J., Hingand J., Guilloteau P., 1989. Digestion des protéines de pois et de soja chez le veau préruminant. 1. Taux circulants de nutriments, formation d'anticorps et perméabilité intestinale aux macromolécules. Reprod. Nutr. Dev., 29, 413-424.

Petit H.V., Ivan M., Brisson G.J., 1989. Digestibility measured by fecal and ileal collection in preruminant calves fed a clotting or a nonclotting milk replacer. J. Dairy Sci., 72 , 123-128.

Peyraud J.L., 1983. Role respectif des enzymes de l'hôte et de la flore intestinale dans la digestion de l'amidon et de ses dérivés (produits amylacés) chez l'agneau préruminant. Thèse de Doctorat, ENSAR, Rennes, France, 173 p.

Raven A.M., Robinson K.L., 1958. Studies of the nutrition of the young calf. A comparison of starch, lactose, and hydrogenated palm oil, with butterfat, in milk diet. Brit. J. Nutr., $12,469-482$

Renner R., Hill F.W., 1961. Factors affecting the absorbability of saturated fatty acids in the chick. J. Nutr., 74, 254-258.

Ribadeau-Dumas B., 1979. Progrès récents dans la biochimie des protéines du lait. Revue Laitière Française, 371, 59-86.

Roy J.H.B., Stobo I.J.F., Gaston H.J., Greatorex J.C., 1970. The nutrition of the veal calf. 2. The effect of different levels of protein and fat in milk substitute diets. Brit. J. Nutr., $24,441-457$.

Sauvant D., Perez J.M., Tran G., 2004. Tables de composition et de valeur nutritive des matières premières destinées aux animaux d'élevage : porcs, volailles, bovins, ovins, caprins, lapins, chevaux, poissons. INRA Editions, Versailles, France, 304p.

Savary P., 1966. Sur la solubilisation micellaire des acides palmitique, stéarique et oléique dans les solutions d'acides biliaires conjugués. Biochim. Biophys. Acta, 125, 328-334.

Scanff P., Savalle B., Miranda G., Pelissier J.P., Guilloteau P., Toullec R., 1990. In vivo gastric digestion of milk proteins - Effect of technological treatments. J. Agric. Food Chem., 38, 1623-1629.

Scanff P., Yvon M., Thirouin S., Pelissier J.P., 1992a. Characterization and kinetics of gastric emptying of peptides derived from milk proteins in the preruminant calf. J. Dairy Res., $59,437-447$.

Scanff P., Yvon M., Pelissier J.P., Guilloteau P., Toullec R., 1992b. Effect of some technological treatments of milk on in vivo gastric emptying of immunoreactive whey proteins. Lait, 72, 43-51.

Sissons J.W., 1981. Digestive enzymes of cattle. J. Sci. Food Agric., 32, 105-114.

Ternouth J.H., Roy J.H.B., Shotton S.M., 1976. Concurrent studies of the flow of digesta in the duodenum and of exocrine pancreatic secretion in calves. 4 . The effect of age. Brit. J. Nutr., 36, 523-535.

Ternouth J.H., Stobo I.J.F., Roy J.H.B., Beattie A.W., 1985. The effect of milk substitute concentration upon the intake, digestion and growth of calves. Anim. Prod., 41, 151159 .

Terosky T.L., Heinrichs A.J., Wilson L.L., 1997. A comparison of milk protein sources in diets of calves up to eight weeks of age. J. Dairy Sci., 80, 2977-2983.

Thivend P., 1979. La digestion des glucides chez le veau non sevré. Ann. Nutr. Alim., 33, 233-245.

Toullec R., 1988. Alimentation du veau de boucherie. In : Alimentation des bovins, ovins et caprins, Jarrige R. (Ed). INRA, Paris, France, 185-199.

Toullec R., Felinski L., 1971. Hydrolyse des triglycérides à chaine longue dans la caillette du veau préruminant. Ann. Biol. Anim. Bioch. Bioph., 11, 315-317.

Toullec R., Formal M., 1998. Digestion of wheat protein in the preruminant calf: ileal digestibility and blood concentrations of nutrients. Anim. Feed Sci. Technol., 73, 115-130.

Toullec R., Grongnet J.F., 1990 Remplacement partiel des protéines du lait par celles du blé ou du maïs dans les aliments d'allaitement : influence sur l'utilisation digestive chez le veau de boucherie. INRA Prod. Anim. 3, 201-206.

Toullec R., Lallès J.P., 1995. Digestion dans la caillette et l'intestin grêle. In : Nutrition des ruminants domestiques: ingestion et digestion. Jarrige R., Ruckebusch Y., Demarquilly C. Farce M.H., Journet M. (Eds) INRA Editions, Paris, France, 527-581.

Toullec R., Mathieu C.M., 1969. Utilisation digestive des matières grasses et de leurs principaux acides gras par le veau préruminant à l'engrais. Influence sur la composition corporelle. Ann. Biol. Anim. Bioch. Bioph., 9, 139 160.

Toullec R., Mathieu C.M., 1971. Utilisation digestive des matières grasses par le veau préruminant à l'engrais : influence du taux d'introduction dans les aliments d'allaitement. Ann. Zootech., 20, 247-250.

Toullec R., Thivend P., Mathieu C.M., 1971. Utilisation des protéines du lactosérum par le veau préruminant à l'engrais. 1. Vidange stomacale comparée du lait entier et de deux laits de remplacement ne contenant que des protéines de lactosérum comme source de matières azotées. Ann. Biol. Anim. Bioch. Bioph., 11, 435-453.

Toullec R., Frantzen J.F., Mathieu C.M 1974. Influence de la coagulation des protéines du lait sur l'utilisation digestive d'un lait de remplacement par le veau préruminant. Ann.
Zootech., 23, 359-364.

Toullec R., Patureau-Mirand P., Thivend P. Vermorel M., 1975. Bases physiologiques de la réalisation des aliments d'allaitement pour veaux. L'Alimentation et la Vie, 63, 69-100.

Toullec R., Coroller J.Y., Thivend P., 1977. Aliments d'allaitement. In : Le veau. Anatomie, physiologie, élevage, alimentation, production, pathologie. Mornet P., Espinasse J. (Eds). Maloine, Paris, France, 171-184.

Toullec R., Thivend P., Vermorel M. Guéguen L., 1978. Veaux. In : Alimentation des ruminants : principes de la nutrition et de l'alimentation des ruminants, besoins alimentaires des animaux, valeur nutritive des aliments. Jarrige R. (Ed), INRA Editions, Versailles, Paris, France, 245-274.

Toullec R., Lallès J.P., Bouchez P., 1994. Replacement of skim milk with soya bean protein concentrates and whey in milk replacers for veal calves. Anim. Feed Sci. Technol., 50, 101-112.

Troccon J.L., Toullec R., 1989. Aliments d'allaitement pour veaux d'élevage. Remplacement de la poudre de lait écrémé par d'autres sources protéiques. INRA Prod. Anim., 2, 117-128.

Tukur H.M., Pardal P.B., Formal M., Toullec R., Lallès J.P., Guilloteau P., 1995. Digestibility, blood levels of nutrients and skin responses of calves fed soyabean and lupin proteins. Reprod. Nutr. Dev., 35, 27-44.

Vaique E., 2009. Synthèse de triglycérides structurés ou fluorescents pour l'étude du métabolisme lipidique. Thèse de Doctorat, Université Bordeaux 1, France, 228p.

Valles E., 1980. Les protéases gastriques bovines utilisées en fromagerie. Thèse de Doctorat, Université Paris-Sud, Centre d'Orsay, Paris, France, 246p.

van den Borne J.J.G.C., Verstegen M.W., Alferink S.J.J., van Ass F.H.M., Gerrits W.J.J., 2006. Synchronising the availability of amino acids and glucose decreases fat retention in heavy preruminant calves. J. Nutr., 136, 2181 2187.

Xu C., Wensing T., Van der Meer R., Beynen A.C., 1997. Mechanism explaining why dietary soya protein $v s$. skim-milk protein lowers fat digestion in veal calves. Livest. Prod. Sci., 52, 219-227.

Xu C., Wensing T., Beynen A.C., 2000. High intake of calcium formiate depresses macronutrient digestibility in veal calves fed milk replacers containing either dairy proteins or whey protein plus soya protein concentrate. J. Anim. Physiol. Anim. Nutr., 83, 49-54.

Yuangklang C., Wensing T., Van den Broek L., Jittakhot S., Beynen A.C., 2004. Fat digestion in veal calves fed milk replacers low or high in calcium and containing either casein or soy protein isolate. J. Dairy Sci., 87, 10511056.

Yvon M., Van Hille I., Pelissier J.P., Guilloteau P., Toullec R., 1984. In vivo milk digestion in the calf abomasum. 2. Milk and whey proteolysis. Reprod. Nutr. Dev., 24, 835843 .

Yvon M., Pelissier J.P., Guilloteau P. Toullec R., 1986. Digestion des protéines du lait dans la caillette du veau préruminant. Reprod. Nutr. Dev., 26, 705-715. 


\title{
Résumé
}

L'essentiel des nutriments nécessaires pour couvrir les besoins nutritionnels du veau préruminant est apporté par l'aliment d'allaitement formulé à base de diverses matières premières d'origine animale ou végétale. La connaissance de leur digestibilité est primordiale pour rationnaliser leur emploi. Cette synthèse fait le point sur les différentes sources de protéines, de matières grasses et de glucides utilisées dans les aliments d'allaitements des veaux de boucherie. A partir de la description des processus digestifs pour les protéines, les lipides et les glucides dans le cas particulier du veau de boucherie, cette synthèse bibliographique montre que les matières premières d'origine laitière (poudre de lait écrémé, poudre de lactosérum, lactose) sont en général très bien digérées par le veau préruminant avec des coefficients d'utilisation digestive apparente supérieurs à $90 \%$ pour tous les nutriments. L'utilisation digestive d'autres matières premières, comme les concentrats de soja, les concentrés protéiques de pomme de terre ou le gluten de blé est plus variable, dépendant largement des traitements technologiques qui sont appliqués. Cependant, les valeurs de digestibilité sont élevées et indiquent que les matières premières d'origine végétale sont des alternatives intéressantes en substitution aux produits laitiers, surtout au-delà du premier mois de vie de l'animal.

\begin{abstract}
Dietary origin and digestion of dietary nutrients in the preruminant calf

Milk-fed veal calves are mainly reared using liquid milk replacer, which is formulated from feedstuffs of animal and vegetable origins. The knowledge of their digestibility by the calf is necessary to optimize their use in animal nutrition. This literature review describes the different sources of proteins, lipids and carbohydrates used in liquid milk replacers and the mechanisms involved in the digestion of dietary proteins, lipids and carbohydrates. The digestibility coefficients for proteins, lipids and carbohydrates of feedstuffs of dairy origin (skim milk powder, whey powder and lactose) are higher than $\mathbf{9 0 \%}$. Nevertheless, the digestibility coefficients of vegetable feedstuffs (soy protein concentrate, potato protein concentrate and wheat gluten) are more variable and depend on the technological treatments they undergo. Nevertheless, these digestibility coefficients are high, which implies that the use of these vegetable feedstuffs is a good alternative to dairy feedstuffs when animals are older than one month.
\end{abstract}

GAUTIER F., LABUSSIÈRE E., 2011. Origines alimentaires et digestion des nutriments chez le veau préruminant. INRA Prod. Anim., 24, 245-258. 